\title{
Defence versus Development: A Theory of Defensive and Expansive Self-Regulation ${ }^{1}$
}

\author{
Jaime Rojas Hernández \\ Asociación para el Desarrollo de la Salud a través de la Atención, Canary Islands, Spain \\ jrojas26682+r@gmail.com \\ https://orcid.org/0000-0002-9291-7881
}

\begin{abstract}
This article presents a macro theory of self-regulation: defensive and expansive self-regulation theory (DERT). It rests on two fundamental assumptions. First, it assumes the coexistence of two competing psychological systems: a defensive system motivated by the need for physical and psychological security, whose function is to protect the organism from harm to life and self, and an expansive system motivated by the needs for competence, relatedness and autonomy, whose function is the development of knowledge, skills, and social support. Second, DERT assumes a threefold distinction regarding consciousness, with psychological processes qualifying as either nonconscious, conscious or metaconscious. Based on the previous assumptions, the theory posits the coexistence of two self-regulatory modes: a defensive regulation, consisting of self-protective responses aimed at avoiding, escaping or fighting survival threats and self-threats, and an expansive regulation, consisting of non-defensive metaconsciousness of one's psychological states and processes. Defensive regulation is assumed to be generally adaptive in the context of survival threats but not in that of self-threats. What is called for in the context of self-threats is expansive regulation, namely non-defensive metaconsciousness of the identifications, evaluations and interpretations of self, others and the world that cause the self-threats in the first place. The theory predicts that defensive and expansive regulation of self-threats cause psychological distress and well-being, and negative and positive interpersonal relationships, respectively.
\end{abstract}

Keywords: self-regulation, defensiveness, expansiveness, metaconsciousness, well-being.

\section{Introduction}

Self-regulation is the capacity to change one's thoughts, emotions, impulses and actions (Baumeister, Schmeichel, \& Vohs, 2007). Failures of self-regulation often result in dire consequences which include, for example, procrastination and underachievement in work and school, financial problems due to inability to save money, overweight and obesity, alcohol and drug addiction, unsafe sex and sexually transmitted diseases, and criminality (Baumeister, Heatherton, \& Tice, 1994; Baumeister, Schmeichel, \& Vohs, 2007). Conversely, better self-regulation has been related to better interpersonal relationships, higher empathy, better psychological adjustment (less psychopathology, higher self-esteem), and optimal emotional responses (Tangney, Baumeister, \& Boone, 2004). Interestingly, self-regulation has been found

${ }^{1}$ The present paper has not yet been published or peer reviewed (date: September 17, 2021). 
to predict positive academic outcomes more robustly than IQ scores (Duckworth \& Seligman, 2005). In a prospective study, Moffitt et al. (2011) found that individual differences in self-regulation in early childhood predicted health, wealth and crime thirty years later. These findings and many others show that self-regulation is a critical capacity from a practical perspective, as well as a very useful construct from a theoretical perspective.

Many theories have been developed over the past forty years to account for different aspects of self-regulation. I will briefly mention some of the most influential ones. Carver and Scheier (1981, 1998, 2016) developed a self-regulatory model inspired by cybernetic control processes, depicting behavior as a goal-directed and feedback-controlled process of moving towards, or away from, goal representations. In their model, Carver and Scheier understand emotions as affective information about how good or bad the progress toward the goal is being. Ego depletion theory (Baumeister, Bratslavsky, Muraven, \& Tice, 1998; Baumeister, 2002) depicts self-regulatory strength as a limited resource: acts of volition, such as decision making and override of dominant impulses, expend the same limited pool of energy and impair subsequent acts of volition. Social cognitive theory (Bandura, 1991) characterizes self-regulation as a key aspect of personal agency and self-direction. In the context of social cognitive theory, self-regulation consists of three processes: self-monitoring, meaning the observation of one's behavior; judgment, that is, the favorable or unfavorable evaluation of one's behavior with regard to personal standards; and self-reaction, namely the affective reactions that follow favorable or unfavorable evaluations of one's behavior. Individuals would then act in ways that result in positive self-reactions and avoid behaviors that lead them to negative self-reactions. Mischel and Ayduk (2004) presented a theory of self-regulation as a cognitive affective processing system composed by interconnected units such as situational appraisals, beliefs, expectations, values, goals, and affect. Zimmerman (2002; Zimmerman \& Campillo, 2003) developed a theory of self-regulated learning, an application of self-regulation to the context of learning. According to the author, self-regulated learning involves three interdependent phases: a forethought phase involving task analysis and self-motivation beliefs, a performance phase that comprises self-control and self-observation, and a self-reflection phase that encompasses self-judgments and self-reactions. Bargh (1990, 1994; Bargh, \& Fitzsimons, 2004) presented self-regulation as a nonconscious process of goal pursuit in contrast to many other theories which require conscious and intentional processes. Regulatory focus theory (Higgins, 1997; Higgins \& Spiegel, 2004) differentiates between two types of regulatory strategies: nurturance-related promotion strategies that seek to approach ideals and realize aspirations, and safety-related prevention strategies that seek to avoid transgressions of oughts or moral standards. Individual differences in terms of judgments and goal pursuit would then be determined by the preferred type of regulatory strategy. Sociometer theory (Leary, 2004; Leary \& Baumeister, 2000) proposes the existence of a specific psychological module, a mechanism whose regulatory function is to monitor the social world in search for socially relevant stimuli, to evaluate their relational value, and to act in such a way so as to minimize the likelihood of social rejection and to maximize that of social acceptance. In the framework of sociometer theory, relational evaluations determine self-esteem or, in other words, self-esteem mirrors the measure to which we consider others to regard us as a valuable or important relationship. Inzlicht and Schmeichel (2016) advanced the shifting priorities model, an alternative explanation of self-regulatory failure to that of ego depletion theory: they propose that self-regulation does not fail because of the depletion of a limited resource, but because self-regulation is inherently aversive and the longer it lasts the more people will be motivated to change to more pleasurable activities. Finally, 
Gottfredson and Hirschi's (1990; Hirschi, 2004) self-control theory of crime proposes that self-control failure is the main determinant of criminal behavior.

The aforementioned sample of models attests to the growing interest aroused by the construct of self-regulation and to the mounting research conducted to extricate it. Yet, in spite of the positive empirical and theoretical progress, there are two important limitations in current self-regulatory theories. The first limitation refers to the fact that most (perhaps all) existing models and theories fail to integrate and account for the most fundamental level of self-regulatory motivation, namely needs. Psychological activity is organized and regulated by physiological and psychological needs. Needs are therefore the driving forces behind most organismic and psychological activity-they are the key to understanding it. However, as stated before, current self-regulation theories do not contemplate this level of analysis. They tend to ignore needs, focusing instead on goals, a motivational level of analysis subordinated to that of needs: goals are learned and contingent, while needs are innate and inevitable. By ignoring needs, psychological theories become oblivious to, and devoid of, the universal and most fundamental motivational level of analysis that gives direction, energy and consistency to psychological activity. As pointed out by Baumeister, Schmeichel and Vohs (2007), "variation in self-regulatory motivation is an important but understudied aspect of self-regulation."

The second limitation of existing theories is that they tend to view consciousness through the traditional dualistic model of nonconscious versus conscious processes. However, it will be argued here that this dualistic model is not the most useful one when it comes to describing and explaining self-regulation. There are both theoretical and empirical reasons for this. Theoretically, this represents a limitation because, from the point of view of self-regulation, it matters greatly whether a certain emotion or wandering thought is or not reflectively attended and aware ${ }^{2}$. Both in the presence and absence of reflective attention, the emotion or thought is said to be "conscious" in the sense that it is experienced and accessed - and it will be described later how that experience can be qualitatively different depending on whether the emotion or thought in question is being attended or not. Nonetheless, reflectively unattended and unaware thoughts and emotions cannot be used for conscious self-regulation. As Baumeister, Schmeichel and Vohs (2007) pointed out, "it is very hard to change a behavior if you are not aware of it. Monitoring one's behavior is an indispensable component to regulating it." Empirically, individual differences in reflective attention and consciousness can be associated with better self-regulation and performance (Smallwood et al., 2007, 2008; Schooler et al., 2011; Baird, Smallwood, Fishman, Mrazek, $\&$ Schooler, 2013).

The aim of this article is to present a theory of self-regulation that overcomes the aforementioned limitations: defensive and expansive regulation theory (DERT). To this end, DERT will first postulate the coexistence of two competing motivational systems rooted in different needs (security vs. competence, relatedness and autonomy), and then it will go on to postulate a threefold distinction with regard to consciousness (viz. nonconscious, conscious, and metaconscious). These postulates will be presented within the perspective of biological evolution to make their plausibility more salient. Based on these two postulates, DERT derives the coexistence of two distinct regulatory modes: a defensive versus an

\footnotetext{
${ }^{2}$ As a matter of fact, most self-regulatory theories seem to agree on the importance of paying attention to, and being reflectively aware of, inner states. This agreement is implicit in the introduction of concepts such as self-monitoring, self-focus, self-attention, self-awareness, self-consciousness, and so on. See, for example, the foundational work of Duval and Wicklund (1972) and of Carver and Scheier (1981).
} 
expansive regulation. Finally, predictions will be made regarding the effects of these regulatory modes on needs' satisfaction, consciousness, well-being, ill-being, and the quality of interpersonal relationships.

The development of DERT required the integration of constructs that are often treated in relative empirical and theoretical isolation, such as motivation, consciousness, self-regulation, evolution, self-reflection, attitude, emotion, appraisal, behavior, well-being, and neural substrates. This kind of theoretical synthesis and the crossing of psychological sub-disciplines that it implies, makes DERT a psychological macro theory. Most of the concepts used in this theory were developed by other authors. Therefore, the originality of this work does not reside in the use of those concepts, but rather in their synthesis: those concepts are related to form a coherent whole, a whole whose parts serve clearly defined psychological and biological functions.

There is one final aspect to be emphasized with regard to the synthetic nature of DERT and the present state of fragmentation of psychological theory and research (Gaj, 2016, and Sternberg, 2005). Although fragmentation in psychology has been interpreted by some authors as a sign of the growing specialization and scientific maturity of the field (Bower, 1993), it has resulted in the isolation of the constructs and phenomena traditionally studied in particular sub-disciplines. Even within subdisciplines authors have called our attention to the fact that the literature in their respective fields consists of pockets of mainly disconnected micro-theories and phenomena (Leary \& Tangney, 2012; Finkel, Fitzsimons, \& vanDellen, 2016; Jones, Kirkland, \& Cunningham, 2014). Studies at the interface of sub-disciplines aiming to explore the relations among their respective constructs and phenomena, and to expand our understanding of the inner workings of the psyche are a rare exception in psychological theory and research. However, as Sternberg (2005) pointed out, it is that kind of studies that are possibly the most interesting, potentially fruitful, and worthwhile pursuing. The present theory is an attempt toward that much-needed theoretical and empirical integration.

\section{Basic concepts: defensiveness, expansiveness and consciousness}

This section will introduce the three fundamental constructs of the theory, namely defensiveness, expansiveness and consciousness. However, before elaborating those constructs, it will be useful to introduce the concept of self-reflection (Kihlstrom, Beer, \& Klein, 2003; Lewis, 1990; Oyserman, Elmore, $\&$ Smith, 2012), a capacity that arises in the course of biological evolution and can play a critical role in the emergence of new defensive, expansive and conscious processes. In the context of this theory, self-reflection is conceptualized as the capacity of psychological processes to take other psychological processes as their object or, alternatively, as the capacity of psychological processes to refer to themselves. To be more specific, with the development of this reflexive capacity, humans are able to pay attention to their own thoughts and emotions, to form a self-concept and think about themselves, to anticipate dangers, benefits and the possible consequences of their actions, to regulate themselves accordingly, to plan their future in advance, or to experience emotions in relation to themselves-as in the case of self-evaluative emotions or self-esteem. Thus, the emergence of self-reflection affords a great deal of new psychological processes and behaviors that have considerable adaptive value (Leary, 2004). 
Humans are, by no means, the only animals with reflexive capacities. Indeed, many other species are known to pass, for instance, the self-recognition test (Mitchell, 2012; Mashour \& Alkire, 2013).

At this point, it will be useful to make a terminological distinction. Henceforth, the term "reflective" will be employed to refer either to animal species that have reflexive capacities or to their reflexive behaviors and psychological processes. Conversely, the term "pre-reflective" will be used to refer to animal species that lack reflexive capacities, as well as to their psychological processes and behaviors. The term "pre-reflective" may also be used to refer to the psychological processes and behaviors of reflective animals that do not require the use of their reflexive capacities.

Before starting the presentation of the basic concepts, it is important to frame them within the organismic paradigm. Living organisms are characterized by functional unity and development (Ryan \& Deci, 2017, p. 32). The functional unity, or self-organization, of an organism refers to the view that it is a complex structure whose parts depend on each other and serve specific functions that are required for the maintenance and preservation of the whole (Ruiz-Mirazo, Etxeberria, Moreno, \& Ibáñez, 2000). Therefore, the activity of a part can only be properly understood in the context of the whole, that is, in relation to the other parts, and never in isolation. On the other hand, the developmental characteristic of organisms refers to their tendency to expand their structures toward greater differentiation, organization and assimilation (von Bertalanffy, 1968). In sum, living organisms are complex structures that tend to maintain themselves and develop towards greater differentiation and assimilation. DERT assumes that, in the psychological domain, these tendencies are organized by needs, and that psychological needs constitute what Tooby and Cosmides (2015) call the "universal human nature." Needs organize thoughts, emotions and actions in ways intended to satisfy them. In turn, at the biological level of analysis, needs can be conceptualized as the phylogenetic result of the evolutionary pressures of natural selection.

DERT postulates the coexistence of two competing psychological systems, both of which serve the distal function of self-preservation: a defensive system motivated by a need for security and whose proximal function is to protect from harm to life and self; and an expansive system motivated by the needs for competence, relatedness and autonomy, and whose proximal function is the development of knowledge, skills, and social support. These two psychological systems, their respective underlying needs, and their dynamics are assumed here to represent the universal human nature.

Let us now turn to the characterization of the defensive system.

\subsection{Defensive system}

The defensive system is a set of interdependent cognitive, affective and behavioral elements that work together to protect the organism from harm. The most characteristic elements of this system include threat appraisal at the cognitive level, fear and anxiety at the affective level, avoidance, escape and aggression at the behavioral level, and stress and tension at the somatic level. In general, when a stimulus is appraised as a threat, it will be followed by a response of stress and fear, which will in turn trigger self-protective responses (e.g., avoidance, fighting) aimed at neutralizing the threat and reducing stress and fear. If the stimulus, however, is appraised as a resource or benefit, it will be followed by a response of excitement, approach and exploitation.

Defensive motivation. The activity of the defensive system is motivated by the need for security: the universal tendency to neutralize perceived threats to life and self. The need for security causes organisms to avoid, escape, fight or otherwise neutralize life-threatening and self-threatening stimuli, and 
to approach life-supporting and self-supporting stimuli. Pre-reflective organisms have a need for exclusively physical security, which involves avoiding death and physical damage from external, material threats—e.g., a predator. This kind of threats will be termed 'survival threats.' On the other hand, reflective organisms, such as humans, have a need for both physical and psychological security. The need for psychological security is the tendency to reduce perceived threats to the self. Threats to the self-henceforth 'self-threats'-include threats to the self-concept, self-esteem, identities, beliefs, cultural values and worldviews, goals, or future plans. Self-threats may be triggered by outer stimuli that provide negative or disconfirming information about the self (e.g., a failure, a social rejection) or by inner stimuli (e.g., worries about the future, ruminations about past negative experiences, negative reflected appraisals).

It should be noted that the nature of survival threats is different from that of self-threats: the former are present, objective, physical dangers to the material integrity of the organism; the latter are perceived dangers to the integrity of one's self-esteem, self-concept, beliefs, values, goals, and, more generally, to any other self-categorizations and self-relevant meanings that are important for the individual.

The conceptualization of security as a physiological and psychological need is warranted because when threat appraisal and the consequent stress are acute and chronic, they will invariably result in loss of health, immunosuppression, inflammation, multiple organ and tissue damage, psychological disorder, disease and, eventually, death (Selye, 1974, 1983; Cohen, Janicki-Deverts \& Miller, 2007; Mariotti, 2015). A certain measure of security is thus necessary for optimal health and functioning. Additionally, the need for security meets all the criteria posited by Baumeister and Leary (1995) for a motive to be considered a basic need.

DERT assumes security to be the dominant psychological need. That is to say that when an organism perceives a severe threat to life or self, the natural tendency will be the provisional subordination of all other needs and action tendencies to self-protective behaviors in order to minimize damage to life or the self and ensure survival. Only when a relative degree of security has been restored, can other needs continue to control behavior. Under conditions of moderate threat, however, security will compete with other needs for the organization and regulation of thought, emotion and action.

Defensive appraisals. Defensive appraisals in pre-reflective organisms consist of the evaluation of the survival value of external stimuli. External stimuli may thus be evaluated as either life-supporting (e.g., food, a potential mate) or life-threatening (e.g., a conspecific rival, a predator). While life-supporting stimuli feel appetitive and are therefore approached, life-threatening stimuli feel aversive and are avoided. It is not the intention of the present theory to provide an exhaustive account of the appraisal process, but rather to lay out the general structure and activity of the defensive system. For a detailed model of the inner structure and process of appraisals, see, for instance, Lazarus (1966, 1991a, 1991b; Lazarus \& Folkman, 1984) or Scherer, Schorr, and Johnstone (2001).

Reflective organisms are not only capable of appraisals of the survival value of external stimuli but also of self-value appraisals. The latter refer to evaluations of the value to the self of external and internal stimuli: whereas negative and disconfirming information about the self are evaluated as self-threatening, positive or confirmatory information about the self are evaluated as self-supporting. As with survival-value appraisals, self-threatening stimuli feel aversive and are therefore avoided, while self-supporting stimuli feel appetitive and are approached. A particularly important kind of defensive appraisal that characterizes reflective organisms are self-evaluations. Self-evaluations are appraisals of one's worth as an individual, and such interpretations are typically contingent on meeting internalized 
cultural standards, expectations, values and norms. Yet another potential form of reflective, defensive appraisal are reflected appraisals, that is, the attribution of how others perceive and evaluate us.

It is important to address here the issue of the adaptive value of defensive appraisals. From an evolutionary point of view, the adaptive value of survival-value appraisals is evident. Meanwhile, self-evaluations are adaptive in that they make individuals conform to the expectations, values and norms of their group, thereby increasing the probability of gaining the group's acceptance and surviving. The adaptive value of self-value appraisals lies in the classification of stimuli according to their potential to either benefit or harm the self, that is, one's self-concept, goals, identities, values, and so on. Such a classification organizes and directs thoughts, emotions and behavior so as to prevent future harms and promote future benefits. As for reflected appraisals, their adaptive value can be found in the possibility to imagine others' expectations and motivations and to anticipate their behavior; this allows individuals, among other things, to conform to the group and to gain its acceptance and protection.

Defensive evaluations can be either biologically determined or acquired through experience. Biologically determined evaluations in humans include those of stimuli that naturally elicit joy (e.g., food, a potential mate), fear (like spiders, snakes, heights, loud noises), disgust (e.g., rotten food, body fluids, worms, cockroaches) or anger (e.g., pain, aversive stimuli, goal obstruction). On the other hand, evaluations can be acquired experientially (for instance, liked and disliked individuals, foods and activities) or culturally (e.g., money, success). Furthermore, pain and pleasure stand in a causal relation to defensive evaluations because stimuli that elicit pain or pleasure will be automatically evaluated as negative and positive, respectively.

The concept of defensive appraisals presented here is related to the factorial structure found by Osgood, May, and Miron (1975) in their research of the dimensions of affective meaning. These researchers found that scales of affective meaning across cultures were underlied by three universal factors: evaluation (whether a stimulus is beneficial or harmful, good or bad), potency (whether it is weak or strong) and activity (whether it is active or passive). The concept of defensive appraisal is most intimately linked to the evaluation factor. However, the three factors found by the authors have a defensive function. After all, it is clearly useful and adaptive to classify stimuli according to their beneficial or dangerous potential, their strength, and their level of activity. The different combinations of these dimensions organize responses to stimuli according to their survival value (e.g., individuals will respond differently to a person that they evaluate as bad, strong and active than to a person that they evaluate as good, strong and active).

Defensive affect. Several forms of affect and their corresponding core relational themes (Lazarus, 1991a; p. 122) can be assigned distinctive defensive functions: fear or fright (presence of an immediate and specific physical danger), anxiety (presence of uncertain threat), anger (aversive stimuli, goal frustration, offense against the self), shame (failure to live up to social standards), guilt (transgression of moral imperatives), envy (wanting what others have), jealousy (resentment of third party for loss or threat to another's affection), disgust (ingestion of, or proximity to, indigestible object or idea), or hubris (exaggerated sense of one's accomplishments, capacities and value). Some of the aforementioned forms of affect are pre-reflective (e.g., fright, anger) whereas others are strictly reflective (e.g., self-conscious emotions like guilt, shame or hubris; see Lewis, 2016); however, all of them are defensive in the measure that they are motivated by the need for security and underlied by evaluations of threat or support to life or the self. 
DERT assumes that negative defensive affect is stronger and more compelling than positive defensive affect for the evolutionary reason that negative affect has a graver implication for survival or the self, namely that it is a signal of a perceived danger. This assumption is consistent with the negativity bias (Larsen \& Prizmic, 2008), the law of hedonic asymmetry (Frijda, 1988; 2007) or the evidence of affective asymmetries (Cacioppo, Berntson, Norris, \& Gollan, 2012; Cacioppo, Larsen, Smith \& Berntson, 2004; Taylor, 1991).

Defensive behavior. When a stimulus is evaluated as a threat to life or the self, the natural defensive behavioral response is self-protection in the form of (a) avoidance, that is, the anticipation and prevention of the occurrence of the stimulus; (b) escape, namely to get out of the way of the stimulus once it has already occurred; and (c) aggression or fight, whenever the stimulus cannot be avoided or escaped. On the other hand, when a stimulus is evaluated as a support for life or the self, the natural defensive response will be approach. Other defensive behaviors have a strictly social nature: this is the case of ingroup favoritism and outgroup discrimination. It is assumed here that social identity is part of the defensive system and sufficient to trigger such behaviors, as demonstrated by the minimal group paradigm (Diehl, 1990).

Defensive memory. The concept of defensive memory refers to the totality of defensive evaluations stored and potentially active within an organism. As stated above, in reflective organisms like human beings, many of these evaluations are derived from internalized cultural standards and generally present themselves in form of affect. These stored evaluations are then automatically retrieved and activated when the evaluated stimulus presents itself, giving rise to an affective response that directs behavior in a way that resembles somatic markers (Bechara \& Damasio, 2005). Thus, defensive memory can be conceptualized as a form of affective memory and it may prove a useful predictor of psychological distress. DERT assumes that the number and frequency of defensive evaluations (especially self-value appraisals, reflected appraisals, and self-evaluations) correlate positively with psychological distress. It further assumes that defensive evaluations are the main cause of psychological distress.

More specifically, the self-evaluations stored in defensive memory cause the phenomenon of fragmentation, that is to say, the degree to which individuals appraise as self-supporting or self-threatening (i.e., as good or bad) their own thoughts, emotions, impulses, behaviors, personality traits, and so on. Again, fragmentation is assumed here to cause and correlate with psychological distress. Note that fragmentation is a defensive manifestation that is only possible with the emergence of self-reflection.

Antecedents of defensiveness. Threat appraisals, stress and defensive reactions have situational and dispositional antecedents (Lazarus, 1966; Lazarus \& Folkman, 1984). Among their situational antecedents, which are the most proximal to defensive behavior, there are stressors in the form of threats to life, goals, self-esteem and self-concept. In turn, the dispositional antecedents of defensiveness include goals, insecure attachment, fragile self-esteem and low self-efficacy. As suggested by Lazarus (1991b), when a stimulus is interpreted as being harmful to one's goals, it is evaluated and perceived as a threat. Therefore, goals are an important personal antecedent of threat appraisal and defensiveness. As for insecure attachment, especially when it takes place at an early age, it possibly represents one of the most distal antecedents of defensiveness (for an account of attachment theory, see Bowlby, 1969, 1988; see also Cassidy, 2016, or Ma, 2006). Insecure attachment develops in children when they do not receive consistent protection, support, reassurance, or affection from their parents when faced with adversity or threats. Insecure attachment, in turn, results in the development of insecure internal working models-i.e., generalized expectations of early insecure attachment, often extrapolated to later relationships- that 
would result in greater fear, stress and defensive responses (psychobiological evidence for this assumption can be found in Meaney et al., 1996; Champagne, Diorio, Sharma, \& Meaney, 2001; Zhang, Chrétien, Meaney, \& Gratton, 2005; Claessens et al., 2011; for a review, see Polan \& Hofer, 2016). The construct of self-esteem represents how persons evaluate and feel about themselves and, more concretely, fragile self-esteem refers to self-feelings that are based on meeting external or internal contingencies, demands or standards (Kernis, 2003). Fragile self-esteem is an important dispositional antecedent of defensiveness because individuals with this trait do not have a secure base of positive self-feelings and are constantly trying to prove to themselves and others their self-worth by meeting social standards. This search for self-verifying and self-enhancing information is motivated by the need for security. When individuals get information that is self-threatening or self-disconfirming, they react defensively and aggressively against the source of that information. Self-efficacy refers to the belief that one is able to effect desired changes on the environment, others or oneself (Bandura, 1982). Low self-efficacy results in the perception of insufficient resources and stress in the face of real or imagined threats (Jerusalem \& Schwarzer, 1992). Thus, low self-efficacy is an important antecedent of threat appraisal and defensive behavior.

A very important antecedent of defensiveness is the hedonic value of experiences, namely pain and pleasure. While painful experiences and situations are automatically negatively evaluated, pleasant experiences are automatically positively evaluated. Particularly relevant is the pain and distress derived from the frustration of the needs for competence, relatedness and autonomy (these needs will be discussed in the following section). By means of this hedonic mechanism, stimuli and experiences are quickly and efficiently tagged as either dangerous or beneficial, thus directing the organism away from potential harm and toward safety.

One last important antecedent of defensiveness are cultural values. Human beings internalize the values, standards and norms of their culture through observation, rewards and punishments. Then these cultural values become the individual's criteria for the desirability of particular behaviors, personality traits, etc. Once internalized, cultural values shape defensive evaluations, especially self-evaluations but also self-value appraisals and reflected appraisals.

Neural substrates of defensiveness. The defensive system is supported by a large network of interconnected neural clusters that involve the processing of aversive and appetitive information. According to Cacioppo, Larsen, Smith \& Bernston (2004), the neural loci responsible for the processing of aversive information (i.e., threat appraisals) include the central amygdala and the bed nucleus of the stria terminalis, whereas the loci involved in appetitive information processing (i.e., positive appraisal) include the nucleus accumbens, ventral pallidum and paraventricular nucleus. The authors also point out the existence of other loci that are involved in both aversive and appetitive information processing, such as the hypothalamus, anterior cingulate cortex and orbitofrontal cortex. They further emphasize the mounting evidence of the distinct loci responsible for separate processing of appetitive and aversive information.

The sympathetic nervous system, a component of the autonomic nervous system, may also be considered a neural substrate of the defensive system. Its function is to activate defensive responses - commonly referred to as "fight or flight"-when faced with potential threats (e.g., Cannon, 1915; Jansen et al., 1995).

For a synthesis of the main characteristics of the defensive system, see Table 1. For a non-exhaustive list of typical defensive manifestations, see Table 2 . Note that the listed manifestations can only be conceived as defensive when they are motivated by the need for security. 
Table 1. Characteristics and constituent elements of the defensive and expansive systems.

\begin{tabular}{|c|c|c|}
\hline & Defensive system & Expansive system \\
\hline $\begin{array}{l}\text { Distal } \\
\text { function }\end{array}$ & \multicolumn{2}{|c|}{ Self-preservation } \\
\hline $\begin{array}{l}\text { Proximal } \\
\text { function }\end{array}$ & Protection from harm to life and self & $\begin{array}{l}\text { Development of skills, knowledge and social } \\
\text { support }\end{array}$ \\
\hline Motive & $\begin{array}{l}\text { Need for physical and psychological security } \\
\text { Extrinsic, controlled motivation }\end{array}$ & $\begin{array}{l}\text { Needs for competence, relatedness, autonomy } \\
\text { Intrinsic, autonomous motivation }\end{array}$ \\
\hline Appraisal & $\begin{array}{l}\text { Survival-value and self-value appraisals; } \\
\text { reflected appraisal; self-evaluations }\end{array}$ & Competence, relatedness, autonomy \\
\hline Affect & $\begin{array}{l}\text { Satisfaction: peace, tranquility, relief } \\
\text { Frustration: fear, anxiety, anger, disgust, guilt, } \\
\text { shame, stress, tension }\end{array}$ & $\begin{array}{l}\text { Satisfaction: efficacy, connectedness, } \\
\text { self-determination } \\
\text { Frustration: helplessness, loneliness, } \\
\text { controlledness }\end{array}$ \\
\hline Behaviors & $\begin{array}{l}\text { Negative evaluation: avoidance, escape, fight } \\
\text { Positive evaluation: approach }\end{array}$ & $\begin{array}{l}\text { Exploration, manipulation, play, curiosity, social } \\
\text { interaction and support, cooperation, altruism }\end{array}$ \\
\hline Memory & $\begin{array}{l}\text { Totality of stored defensive evaluations and } \\
\text { affect }\end{array}$ & $\begin{array}{l}\text { Concepts, theories, knowledge, skills, } \\
\text { interpersonal affective bonds }\end{array}$ \\
\hline Antecedents & $\begin{array}{l}\text { Situational: stressors (i.e. threats to life or self), } \\
\text { conditional parental regard } \\
\text { Dispositional: insecure attachment, fragile } \\
\text { self-esteem, low self-efficacy, goals; pain and } \\
\text { pleasure; cultural values }\end{array}$ & $\begin{array}{l}\text { Situational: empowering vs discouraging, loving } \\
\text { vs rejecting, validating vs controlling } \\
\text { environments } \\
\text { Dispositional: secure attachment, optimal } \\
\text { self-esteem, high self-efficacy }\end{array}$ \\
\hline $\begin{array}{l}\text { Neural } \\
\text { substrate }\end{array}$ & $\begin{array}{l}\text { Central amygdala, bed nucleus stria terminalis } \\
\text { (threat appraisal); nucleus accumbens, ventral } \\
\text { pallidum, paraventricular nucleus (positive } \\
\text { appraisal); sympathetic nervous system (fight } \\
\text { or flight response) }\end{array}$ & $\begin{array}{l}\text { SEEKING system: ventral tegmental area and } \\
\text { its dopaminergic projections to nucleus } \\
\text { accumbens, medial forebrain bundle, lateral } \\
\text { hypothalamus, and ventromedial prefrontal } \\
\text { cortex }\end{array}$ \\
\hline
\end{tabular}

Table 2. Typical manifestations of defensiveness and expansiveness.

\begin{tabular}{|l|l|}
\hline Defensiveness & Expansiveness \\
\hline $\begin{array}{l}\text { Cognitive manifestations: survival-value and } \\
\text { self-value appraisals, reflected appraisals, } \\
\text { self-evaluations, resistance to change, self-serving } \\
\text { biases (e.g., self-enhancement, self-verification, } \\
\text { confirmation bias; attentional, memory and } \\
\text { interpretation biases), egotism, self-deception, distrust, } \\
\begin{array}{l}\text { self-other comparison; uncertainty intolerance, } \\
\text { frustration intolerance, self-judgments, shoulds and } \\
\text { shouldn'ts, mental time travel (e.g., rumination, worry), } \\
\text { self-justification, cognitive closure, social desirability, } \\
\text { denial, prejudice, ethnocentrism, stereotyping, } \\
\text { stereotype-threat, racism, dogmatism, authoritarianism, }\end{array}\end{array}$ & $\begin{array}{l}\text { Cognitive manifestations: self-efficacy, optimism, } \\
\text { learning and acquisition of new skills, competences and } \\
\text { knowledge (e.g., academic, professional, athletic, } \\
\text { cultural, self-knowledge), curiosity, openness to } \\
\text { experience and change, suspending assumptions, } \\
\text { absorption, interest taking, reappraisal, cognitive } \\
\text { restructuring, trust in others, empathy, theory of mind }\end{array}$ \\
\hline $\begin{array}{l}\text { Affective manifestations: fear (e.g., of rejection, } \\
\text { failure, suffering, death, etc.), anxiety, anger, irritability, }\end{array}$ & $\begin{array}{l}\text { Affective manifestations: Satisfaction: efficacy, vitality, } \\
\text { joy, excitement, awe, pride, optimal self-esteem, }\end{array}$ \\
\hline
\end{tabular}


neuroticism, stress, ego-involvement, self-pity, offence, resentment, hatred, inadequacy, jealousy, envy, greed, guilt, shame, hubris, insecure attachment, fragile or contingent self-esteem happiness, empathy, connectedness, belongingness, affection, love, freedom, choice, responsibility; Frustration: helplessness, powerlessness, sadness, rejection, loneliness, isolation, desolation, affliction, bitterness, grief, controlledness, pressure, alienation, meaninglessness

Behavioral manifestations: exploration, inquiry, play, taking risks, novelty seeking, creativity, social interaction, cooperation, prosocial action, caring for others, doing gratifying activities

impulsiveness, impatience, defence of views of self, others and world, pursuit of ideal self, ingroup favoritism, outgroup discrimination

\subsection{Expansive System}

As seen in the previous section, complex organisms are endowed with a defensive system that protects them against harm and danger. The defensive system is largely reactive to stimuli that are interpreted as threatening or supporting. However, such defensive action tendencies fail to reflect the spontaneous, active, self-determined action tendencies that many complex organisms display, like exploration, play or social interactions. Thus, to give a more complete account of animal nature in general and human nature in particular, an expansive or developmental system has to be considered that explains self-determined behavior. The views presented in this section are largely inspired by self-determination theory (Ryan \& Deci, 2017).

The proximal function of the expansive system is to assimilate and master external and internal realities, and to establish interpersonal relationships that provide social support. This system is termed 'expansive' because it motivates the development of the individual's capacities, knowledge and social support, all of which are crucial for self-preservation.

Expansive motivation. The thought, emotion and action tendencies of the expansive system are organized by the needs for competence, autonomy and relatedness. Competence represents the need for the mastery of external and internal reality, and it encompasses exploration, manipulation, pursuit of novelty and challenge, play, creativity, curiosity, interest taking, flow, and learning of new skills and knowledge. White $(1959,1963)$ described competence —or, as he often called it, 'effectance'-as the motivation to interact effectively with one's environment, or, alternatively, as the satisfaction or pleasure in producing effects or in being a cause. Relatedness is the need for reciprocal affection and intimacy in interpersonal relationships (Baumeister \& Leary, 1995). It involves feeling deeply connected to others, being significant to others, caring for others and being cared for by others, as well as unconditional affection and acceptance. Facets of relatedness include, among others, empathy, sensitivity to others' needs and suffering, intimacy, trust, affection, and mutual care. Autonomy, in turn, is the need to perceive that one's actions are determined by one's deeply held values and interests, and not by outer or inner pressures. In other words, autonomy is the need to experience one's behavior as self-determined instead of experiencing it as being governed by external forces that are alien to one's will. The degree of autonomy of an action depends on its perceived locus of causality (the latter, a concept introduced by Heider, 1958, and further elaborated by de Charms, 1968), with more autonomous actions having a more internal locus and with less autonomous actions having a more external locus (Ryan \& Connell, 1989). Manifestations of autonomy can be found in perceptions of control, of choice, of personal freedom (in the sense of lack 
of outer and inner coercion or pressures) and of personal responsibility, as well as in experiences of authenticity and self-congruence.

The reason to consider competence, relatedness and autonomy as part of a single system is that they all must be satisfied for optimal development, functioning, intrinsic motivation, internalization, and well-being (Ryan \& Deci, 2017). Further, the measures of the three expansive needs are generally highly intercorrelated and interdependent (ibid., p. 93).

In pre-reflective organisms, the need for competence encompasses the assimilation and mastery of the environment whereas in reflective animals it additionally encompasses the assimilation and mastery of the psychological reality. As for relatedness, in pre-reflective organisms, it involves the development of relational and cooperative behaviors while in reflective animals it also involves the representation of the thoughts, emotions and intentions of others, that is, the formation of a theory of mind (Premack \& Woodruff, 1978). With regard to autonomy, pre-reflective organisms display intrinsically motivated behaviors like environmental exploration and social interaction whereas reflective organisms additionally display such experiences as responsibility, self-congruence or authenticity.

Expansive appraisals. Expansive appraisals include evaluations of competence, relatedness and autonomy. Competence appraisals are evaluations of one's skills and capacities in specific domains. Competence appraisals depend on attributions following successful or unsuccessful behavioral outcomes, and then determine affect, motivation and performance (e.g., Weiner, 2005; Perry \& Hamm, 2017). According to Weiner (2005), attributions of successes and failures are causal inferences with three dimensions: controllability, stability and locus of causality. Depending on the attributional properties of the perceived cause, individuals infer their competence or incompetence: e.g., if a student attributes a bad grade to lack of effort (i.e., an internal, controllable, unstable cause), this attribution will not result in an appraisal of incompetence and will result in an expectation of future success and higher effort and performance in the future; in contrast, if he attributes the failure to his inability (i.e., an internal, uncontrollable, stable cause), this attribution will result in an appraisal of incompetence and this, in turn, will lead to low expectations of future success as well as low future efforts and performance. High competence is appraised when individuals effect desired changes on the environment or upon themselves, and attribute those changes to their own agency.

Challenge appraisals are interpretations of tasks and demands as opportunities for mastery (Lazarus \& Folkman, 1984). DERT assumes that challenge appraisals are motivated by the need for competence. Whereas threat appraisals result in negative emotions like fear and anxiety, challenge appraisals result in positive emotions like excitement and optimism. Lazarus and Folkman (1984) expressed a similar point by stating that they "do not view threat and challenge appraisals as poles of a single continuum. [...] threat and challenge can occur simultaneously, and must be considered as separate, although often related, constructs" (p. 33). Additionally, reappraisals-i.e., changes to the pre-existing appraisal of a stimulus (Lazarus \& Folkman, 1984) — are also motivated by competence when they seek to assimilate novelty or to resolve contradictions. The same can be said about cognitive restructuring, that is, the modification of dysfunctional beliefs (Beck, Emery, \& Greenberg, 1985; Wright, Brown, Thase, \& Basco, 2017).

Autonomy appraisals are evaluations of the degree to which individuals endorse their own actions and motivations (Dworkin, 1988; Friedman, 2003). According to this view, an action or motive is autonomous to the degree that the individual reflectively endorses it. The reflective element in the previous sentence does not mean that ongoing actions and their motives need to be conscious and 
reflectively endorsed in order to be autonomous, but rather that ongoing autonomous actions and motives would be self-endorsed if the individual were to reflect on them (Ryan \& Deci, 2004). Alternatively, autonomy appraisals may be defined as the degree to which one's actions or motivations are perceived to be compatible with one's deepest values, interests and needs. The factors that can undermine autonomy include rewards and punishments, inner and outer pressures, coercion, threats and fears. Another important point about autonomy is that it is not necessarily undermined by external demands; it is only when individuals do not fully endorse or assent to the requested action or its underlying motivation that they experience a loss of autonomy. In contrast, if the requested action and its motivation are completely compatible with one's deepest values and interests, then the individual could assent to do it with a full sense of autonomy (Ryan \& Deci, 2017). In the latter case, the individual's wholehearted assent to the external demand leads him to experience what de Charms (1968) termed 'internal perceived locus of causality' in spite of the external demand, that is, the individual does not feel like a pawn to external forces but rather that he is, in a way, the origin of the action.

Relatedness appraisals are evaluations of the stability of interpersonal relationships, their intimacy, and their mutuality in terms of affection and care (Baumeister \& Leary, 1995). Another way to conceptualize relatedness would be as a need for mutual sensitivity and responsiveness. According to Baumeister and Leary (1995), optimal satisfaction of relatedness requires individuals to simultaneously meet its different criteria: frequency, stability, positivity of interactions, affectionate concern, care, and mutuality.

Expansive affect. The satisfaction of competence following a significant success leads to a feeling of efficacy or agency, joy, excitement, pride, self-esteem and happiness. On the other hand, a significant failure frustrates one's perception of competence, potentially generating feelings of helplessness or powerlessness or sadness. Exactly which of these emotions ensues after a success or a failure, depends on the inferred locus, controllability and stability of the cause to which that success or failure is attributed (e.g., Weiner, 2005). When it comes to relatedness, its satisfaction brings about feelings of connectedness or belongingness, love, joy, self-esteem, and happiness, whereas its frustration brings about feelings of rejection, loss, loneliness, isolation, desolation, depression, affliction, bitterness, and grief (Baumeister \& Leary, 1995). Finally, the satisfaction of autonomy is associated with feelings of freedom, choice or responsibility while its frustration leads one to feel controlled, pressured, alienated, meaningless or empty (Ryan \& Deci, 2017).

Expansive behavior. The action tendencies motivated by the expansive system are characteristically spontaneous and self-determined. This is not to say that they cannot be occasionally elicited by external events, as when a novel stimulus presents itself. However, they do not require the presence of external events in order to be initiated. This stands in contrast to defensive actions tendencies, which are characteristically reactive in the sense that they are generally reactions to present external or internal stimuli (e.g., a thief, worries). Spontaneous behavior can be observed in humans and in other animal species alike.

As stated above, the actions tendencies promoted by the need for competence range from exploration, manipulation, curiosity, interest taking and learning, to play and creativity. Human babies exhibit these behaviors from the first days of life (Wentworth \& Witryol, 2003), which indicates that these tendencies are biologically selected and genetically determined. Of course, these behaviors are not exclusively human but they are shared by all complex organisms (Byrne, 2013), meaning that they must 
have been selected at a very early phylogenetic stage of biological evolution. These behaviors seek the assimilation of the environment and the development of the skills and knowledge necessary for survival.

The action tendencies motivated by relatedness, such as association, cooperation or altruism, are not universal to complex organisms. Rather, there is a continuum of sociality among animal species that goes from cooperative breeding to communal behavior and eusociality (Crespi, 2001; Choe \& Crespi, 1997). When the benefits of sociality outweigh its costs, social behaviors are believed to increase the survival rates and inclusive reproductive fitness of organisms by providing protection from predators, access to resources, and mating opportunities (Silk, 2007).

Expansive memory. As suggested by Piaget (1952), intelligence is an organizing activity that promotes the active assimilation and accommodation of the environment by the organism. In a brief analysis, Bohm (1996) lays out of how Piaget's theory of intelligence is relevant to the perception and understanding of the physical reality: initially infants seem to live in a world of undifferentiated sensory perception, with no recognizable objects, no sense of self, and no distinction between external world and the self; in the first months and years of life, infants use what Piaget called 'circular reactions,' a set of sensorimotor schemata of coordinated motor outputs and resulting sensory inputs; from this activity, infants and children discover numerous sensorimotor invariant relationships that form the basis for the abstraction of the concepts of permanent object, conservation of substance, space, time, self, and so on; children then go on to relate these concepts by means of sets of more complex schemata, effectively forming theories of larger domains of experience; once these concepts have been abstracted from sensorimotor activity, they inform and structure subsequent perception. DERT assumes this assimilatory activity to be organized by the need for competence. It is through this assimilatory activity that individuals abstract concepts from perception and formulate lay and scientific theories to explain the invariances found in perception. These concepts and theories are conceived here as part of expansive memory.

Skills, whose development is also motivated by the need for competence, are another element of expansive memory. Unlike concepts and theories, skills are a kind of procedural memory (Squire, 1987). They represent the acquired practical knowledge that allows organisms to effect particular desired changes on their environment, a type of knowledge that involves the effective motor execution of particular tasks.

Yet another element of expansive memory are the affective bonds of interpersonal relationships.

Antecedents of expansiveness. The present theory assumes that expansive activity is promoted by secure attachment whereas it is thwarted by insecure attachment styles. There is evidence in adults of a relation between attachment styles and exploration, curiosity and openness (Mikulincer, 1997; Mikulincer \& Arad, 1999; Green \& Campbell, 2000). The concept of conditional parental regard (Assor, Roth, \& Deci, 2004) refers to a parenting style in which parents only give affection and attention to their children when the latter do as they are told or meet certain standards. It implies a motivational conflict between relatedness and autonomy in which in order to get parental affection, children need to give up their autonomy and do as they are told. DERT assumes that the use of conditional parental regard results in lower satisfaction of expansive needs. Evidence for this assumption can be found in Roth, Assor, Niemiec, Ryan, and Deci (2009). An additional potential antecedent (and consequence) of expansiveness is secure self-esteem (Kernis, 2003), meaning the self-esteem that originates from the satisfaction of expansive needs. This non-contingent self-esteem creates a stable sense of wellness and vitality that in turn promotes further expansive activity. Another important antecedent of expansiveness is self-efficacy, with individuals higher in self-efficacy in a particular domain displaying more expansive behaviors. Finally, family, academic or work environments of individuals can have a supportive vs detrimental effect on the 
satisfaction of expansive needs and on expansive behavior (Ryan \& Deci, 2017, p. 12): some environments are need-thwarting vs need-supportive when they are discouraging and overly demanding vs empowering, encouraging, and optimally challenging (competence); invalidating, manipulative, coercive, and controlling vs validating and approving (autonomy); and impersonal and rejecting vs unconditionally accepting, loving, caring, sensitive, and responsive (relatedness).

Neural substrate of expansiveness. Di Domenico and Ryan (2017) suggest that intrinsic motivation and intrinsically motivated behaviors common to mammals, such as exploration, foraging, investigation, curiosity, or interest, depend on a dopaminergic neurobiological system that Panksepp (1998; Panksepp \& Biven, 2012) denominates the SEEKING system. According to Panksepp and Biven (2012), the anatomy of the SEEKING system is composed of the ventral tegmental area and its ascending dopaminergic projections innervating the medial forebrain bundle and lateral hypothalamus, the nucleus accumbens, and the ventromedial prefrontal cortex. The authors maintain that the general purpose of the SEEKING system is to energize behavior in order for organisms to search and explore their environment and find potentially useful resources, "from nuts to knowledge."

See in Table 1 the main characteristics of the expansive system in contrast to those of the defensive system, and in Table 2 a non-exhaustive list of typical manifestations of expansiveness. Note that these manifestations are expansive only in the measure that they are motivated by expansive needs.

Explanatory potential of the defensive-expansive motivational distinction. The distinction between defensively and expansively motivated activity has the potential to explain and integrate a vast array of phenomena and constructs that are typically treated in theoretical and empirical isolation. Table 1 and 2 display but some of them. Some others are often treated in the literature as complements that may be viewed, in the context of the present theory, as defensive versus expansive counterparts, respectively: threat versus challenge appraisals (Lazarus, 1966, 1991a, 1991b; Lazarus \& Folkman, 1984), distress versus eustress (Selye, 1975, 1976), controlled versus autonomous motivation (Ryan, Kuhl, \& Deci, 1997; Ryan \& Deci, 2017, p. 14), competition versus cooperation (Deutsch, 2006), selfish versus prosocial behavior (Baumann, Cialdini, \& Kendrick, 1981; Batson \& Shaw, 1991), performance versus mastery goals (Nicholls, Cobb, Wood, Yackel, \& Patashnick, 1990; Senko, Hulleman, \& Harackiewicz, 2011; Benita, Roth, \& Deci, 2014; Elliot, 1999), obsessive versus harmonious passion for work (Vallerand \& Houlfort, 2003), preference for memorization and surface processing versus understanding and deep processing (Biggs, 2001; Komarraju, Karau, Schmeck, \& Avdic, 2011), public and private self-consciousness, self-reflectiveness and rumination versus internal state awareness and reflection (Burnkrant \& Page, 1984; Trapnell \& Campbell, 1999), negative versus positive rumination (Killingsworth \& Gilbert, 2010), neuroticism and introversion versus openness to experience and agreeableness (Costa \& McCrae, 1992), reactance, power and fame versus autonomy, competence and relatedness (Koestner \& Losier, 1996; Ryan \& Deci, 2017, p. 21), fragile versus secure self-esteem (Kernis, 2003), political conservatism, traditionalism, conformity, authoritarianism, dogmatism, social dominance orientation, and mental rigidity versus liberalism, progressivism, egalitarianism, benevolence, universalism, and integrative complexity (Caprara \& Vecchione, 2013; Piurko, Schwartz, \& Davidov, 2011), power distance, uncertainty avoidance, and masculinity versus femininity (Hofstede, 2011), and the pursuit of subjective well-being versus psychological well-being (Diener, 1984; Ryff, 1989). An exciting avenue of research will be to test the causal link between these phenomena and constructs and their respective underlying motivations. 
Graphical representation. For illustrative purposes, Figure 1 displays one possible visual representation of the defensive and expansive systems inspired by Carver and Scheier's (2016) cybernetic control process of self-regulation. First, a stimulus is represented and then appraised by each system in terms of its underlying needs: security, in the case of the defensive system, and competence, relatedness and autonomy in the case of the expansive system. If the represented stimulus is appraised as not being relevant to the underlying needs, no affective and behavioral responses will follow. In the context of the defensive system, if the stimulus is appraised as a threat, then fear, anxiety, or avoidance will typically follow; if it is appraised as a resource or benefit, then excitement, approach and exploitation will follow. Of course, many other context-specific affective and behavioral responses are possible. The defensive system is reactive in the sense that it is generally activated by present (external or internal) stimuli. The expansive system, in turn, can be activated both spontaneously and by present stimuli: if it is activated by a present stimulus, which is appraised as a gain or loss in competence, relatedness or autonomy, a respective affective increase or decrease in effectance, connection and self-determination will result, with a corresponding behavioral engagement or disengagement; if it is activated spontaneously, its processes are self-initiated and not controlled by external stimuli. Once a system appraises a stimulus as relevant to an underlying need, the resulting affect is stored in memory in relation to its representation (dotted line) so as to direct future behavior. Activated behaviors are intended to satisfy their underlying need: defensive behaviors involve reducing perceived threats and exploiting resources, and they stop as soon as that goal is achieved whereas expansive behaviors involve the exploration of reality and social interactions, and they do not stop even when the underlying need is satisfied.

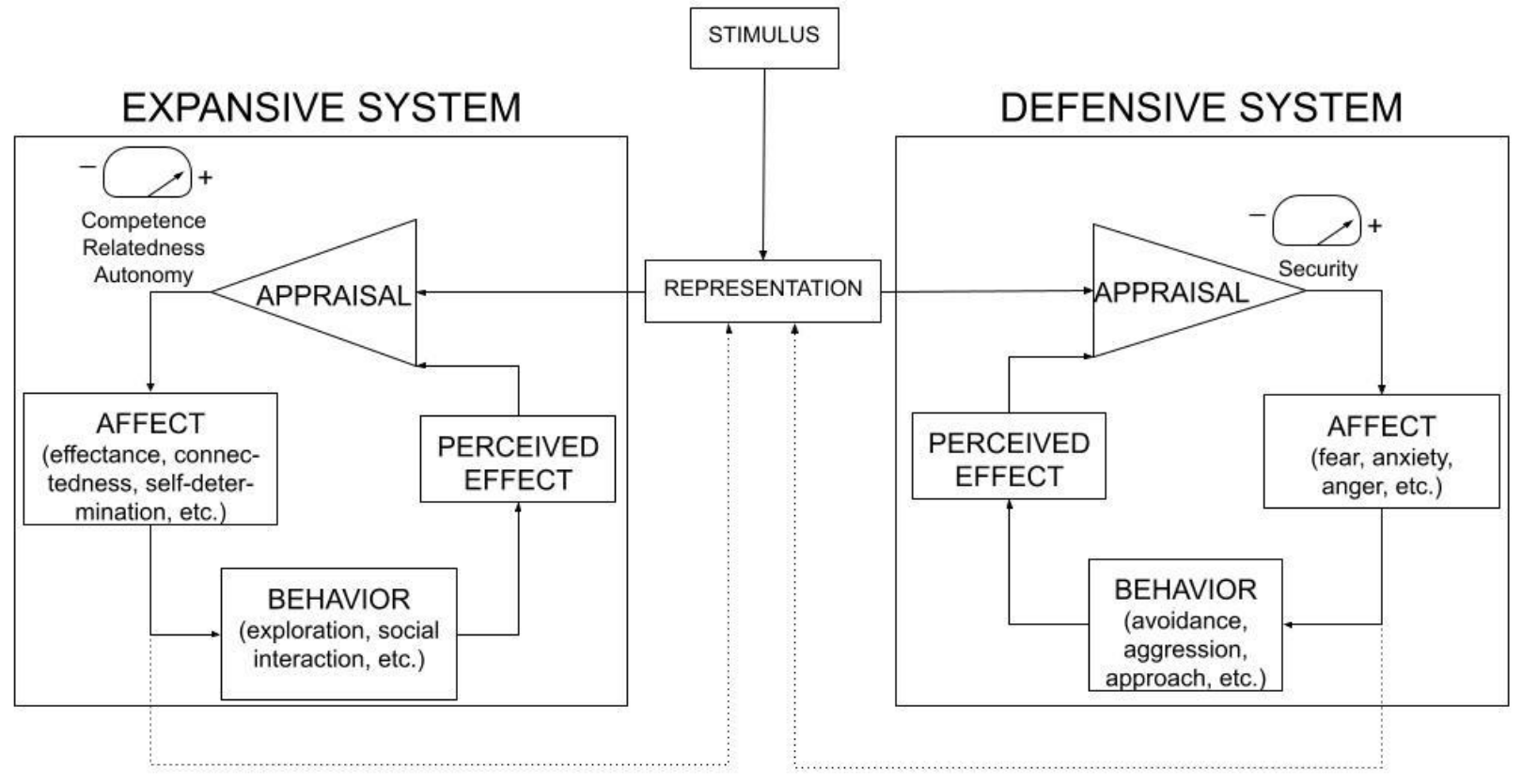

Figure 1. Graphical representation of the defensive and expansive systems as cybernetic control processes. 


\section{Related theories}

Several existing theories can be related to the defensive-expansive motivational distinction presented here. Self-determination theory (SDT; Ryan \& Deci, 2017) posits the existence of three psychological needs for autonomy, competence and relatedness, which must be satisfied for optimal development and wellness. DERT agrees with this central assumption of SDT. However, there are also fundamental differences between the two theories: (a) SDT views security as an exclusively physiological need (ibid., p. 10) whereas DERT views it as both physiological and psychological because most threats that human beings face are symbolic, as in the case of worries about the future or about what others think of them; that is, most threats are about what is possible and not about what is present; (b) SDT does not consider security a need in its own right because it only motivates when individuals feel threatened (i.e., because it is a deficit need as opposed to a growth need; ibid., pp. 254-255) while DERT considers needs all the motives that meet Baumeister and Leary's (1995) criteria regardless of their status as deficit or growth needs; and (c) SDT often portrays defensive processes as derivative from the frustration of expansive needs (ibid., pp. 90-91) whereas DERT assumes that there is just a contingent relation between defensive processes and frustration of expansive needs (the so-called 'hedonic nexus'; see below); further, DERT assumes that the content of threat appraisals is not restricted to the frustration of expansive needs (e.g., as in fear of out-group members, death, poverty, sickness, or spiders); for these reasons, DERT assumes that defensive processes cannot be reduced to the frustration of expansive needs. By explicitly accounting for both expansive and defensive processes, DERT can accommodate SDT while providing a more complete picture of human motivation and behavior.

Terror management theory (TMT; Greenberg, Solomon, \& Pyszczynski, 1997) postulates that the fundamental causal mechanism of defensive processes is death awareness, which would motivate individuals to protect their cultural worldviews and self-esteem in order to buffer death-related anxiety. DERT agrees with TMT that death is one possible content of self-threats and that both self-esteem maintenance and the defence of cultural worldviews are important defensive mechanisms. Yet, there are important points of departure between them: (a) DERT considers that neither death awareness, nor cultural worldview defense, nor self-esteem maintenance play a necessary causal role in defensive processes (i.e., they are merely contingent); DERT assumes that the fundamental causal mechanism of all defensive activity is threat appraisal and reduction; (b) the psychological need that motivates defensive processes is assumed to be self-esteem in the case of TMT, and security in the case of DERT; the consideration of self-esteem as the basic defensive need seems particularly problematic since self-esteem is a strictly reflective phenomenon; and given that defensive processes precede self-reflection, self-esteem lacks phylogenetic continuity between pre-reflective and reflective defensive processes; security, however, as a mechanism of threat appraisal and reduction, does have phylogenetic continuity and is therefore a more parsimonious explanation. Thus, DERT offers an evolutionarily more sound and general explanation of defensive processes than TMT.

Dual-motive depth psychology (DMDP; Pyszczynski, Greenberg, \& Arndt, 2012) is a theory that attempts to explain defensive and expansive processes by integrating TMT and SDT. Hence, DMDP is susceptible to the same theoretical problems outlined above. In addition, TMT and SDT seem hardly compatible because the former assumes self-esteem to be the basic defensive need while the former does not consider self-esteem to be a basic need (Ryan \& Deci, 2017, p. 255) and views defensive processes as 
derivative from expansive processes (ibid., pp. 90-91). Therefore, the aggregate of these two theories cannot yield an internally consistent explanation. To conclude, unlike DERT, DMDP does not provide an integrated model of defensive and expansive cognition, affect and behavior.

Regulatory focus theory (RFT; Higgins, 1997) postulates two types of regulatory strategies: nurturance-related promotion strategies that seek to approach ideals and realize aspirations, and safety-related prevention strategies that seek to avoid transgressions of oughts or moral standards. DERT and RFT concur in that approach and avoidance are important regulatory strategies. Nevertheless, the similar terminology used by both theories (i.e., security and nurturance needs in RFT vs security and expansive needs in DERT) can project a false appearance of correspondence between them. The general discrepancy between the theories can be summarized in two points: (a) while RFT assumes that ideal self-regulation (promotion) is motivated by nurturance and ought self-regulation (prevention) by security, DERT assumes both to be motivated by security (because they involve conformity to social norms and standards in order to be accepted or recognized); and (b) promotion and prevention in RFT are extrinsically motivated actions in that they are controlled by external contingencies (i.e., positive and negative outcomes); thus, none of them can be motivated by expansive needs (DERT's apparent counterpart of RFT's nurturance needs), which are intrinsic motivations. In sum, there is no correspondence between RFT's and DERT's needs. Moreover, the loose definition of RFT's needs and the lack of articulation of how such needs translate into systems of emotion, thought and action, makes an accurate comparison between the two theories impossible. Finally, and in contrast to RFT, DERT is not solely concerned with approach and avoidance but, more generally, with the evolutionary explanation of motivation, affect, cognition and behavior as interdependent elements of coherent psychological systems with defensive and developmental functions.

The exploitation-exploration problem (EEP; e.g., Cohen, McClure \& Yu, 2007) is a decision-making optimization problem that all animals must face constantly: whether to make use of known resources (exploitation) or to search for new resources (exploration). Although DERT does not attempt to address EEP's specific optimization problem, it can explain the exploratory and exploitative behaviors at the psychological level: exploration can be explained by the need for competence, and exploitation by the need for security. Exploration is one of the manifestations of the need for competence- one of DERT's expansive needs. On the other hand, DERT's need for security involves the appraisal of both life-threatening and life-supporting stimuli (the latter include resources), and defensive behavior in relation to life-supporting stimuli involves approach and exploitation. Expansive and defensive needs can thus be conceptualized as the psychological causes of exploration and exploitation, respectively.

The meaning maintenance model (MMM; Heine, Proulx, \& Vohs, 2006) proposes the existence of a need for meaning, a need to build cognitive representations of events so as to be able to relate to them; when these representations are threatened, people would then reaffirm alternative representations to restore meaning. DERT agrees that giving meaning to events is an important motivation and that reaffirming pre-existing views is an important defensive regulatory strategy. However, DERT does not consider meaning-making a need but rather a facet of the need for competence, whose function is the the assimilation of reality by developing adaptive skills and knowledge. In addition, the reaffirmation of worldviews is motivated by the need for security. In this way, DERT's more general framework can accommodate MMM's concepts and findings. 


\subsection{Consciousness}

The third variable that is central to DERT is consciousness. The definition of consciousness has proven elusive (Chalmers, 1996; Güzuldere, 1997). For the purpose of this theory, consciousness is defined as the integrated flux of perceptions, emotions, thoughts and impulses experienced by an individual. This definition highlights the two central elements of consciousness: (1) subjective experience, that is, the observation of particular mental contents, such as the visual perception of color, and (2) the specific phenomenal qualities of those experienced mental contents, that is, what it is like to experience such mental contents (the latter refers to the concept of qualia; see Nagel, 1974). In this context, 'to be conscious' of a particular mental content (e.g., a thought) means that that content is being represented in one's subjective experience. Consciousness can also be characterized in terms of availability, meaning that the individual has privileged and direct access to some mental contents. In humans, consciousness is routinely assessed by means of verbal self-reports (Seth, Baars, \& Edelman, 2005).

In relation to consciousness, psychological processes have been traditionally classified as either nonconscious or conscious (e.g., Kihlstrom, 2007). In this traditional dual model, a threshold is assumed to separate conscious from nonconscious processes. This model further assumes that there is a continuum of both nonconsciousness and consciousness, meaning that some nonconscious processes are further from the threshold of awareness than others, and that some conscious processes are more easily accessible and vivid than others. This notion of the continuum of consciousness does not only apply to specific mental contents and processes but also to the subject as a whole (Güzuldere, 1997; Searle, 1990). In fact, in medical settings, scales are used to establish the overall level of consciousness of patients (Sternbach, 2000; McNarry \& Goldhill, 2004; Kandel, Schwartz, \& Jessell, 2000).

Even though the traditional dual model of conscious versus nonconscious psychological processes is widely used, it is fundamentally limited from a self-regulatory standpoint. The limitation lies in the fact that a particular mental content, such as an emotion, may be conscious but unattended and not reflectively aware. This distinction between experienced but unattended and not reflectively conscious processes versus experienced, attended and reflectively conscious processes is crucial for self-regulatory purposes. An instance of the former is an emotional outburst of anger during a heated argument with one's boss, or one's wandering thoughts while driving. Even if one is not paying attention to, and reflectively conscious of, that anger or those wandering thoughts, one is experiencing them at some level and, in that sense, they are conscious. However, because in that particular moment they were not being attended and reflectively conscious, they could not be used for conscious self-regulation. Therefore, when it comes to regulating psychological processes consciously, it is of crucial importance whether such processes are attended and reflectively conscious. Baumeister, Schmeichel and Vohs (2007) put it simply: "it is very hard to change a behavior if you are not aware of it. Monitoring one's behavior is an indispensable component to regulating it." For that reason, DERT uses an alternative model of consciousness informed by that of Schooler and his colleagues (Schooler, Mrazek, Baird, \& Winkielman, 2015; Winkielman \& Schooler, 2011; Chin \& Schooler, 2009; Schooler, 2002; Schooler, 2001). There is, however, a fundamental difference between the definition of the central concept of metaconsciousness as used in Schooler's model and here, as will be evident later. 
Schooler (2002) proposes three levels of processing with regard to consciousness: nonconscious, conscious, and metaconscious. The following sections consider the characteristics of each level from DERT's perspective.

Nonconscious processing. Psychological processes are nonconscious when they are not represented in subjective experience. Alternatively, nonconscious processes are not subjectively available or accessible, thus resulting in a failure by the subject to experience and communicate them. For an account of nonconscious memory, learning, perception, thought and motivational processes, see Kihlstrom (2007). A paradigmatic nonconscious process is subliminal perception (Kouider \& Dehaene, 2007). When, for example, individuals are subliminally exposed to a masked stimulus and in a subsequent task display discriminatory responses that show that they processed the stimulus, nonconscious perception is in evidence. Additionally, some neurological disorders, like visual neglect, amnesia and blindsight, provide evidence for nonconscious processing (Styles, 2006).

Conscious processing and experience. Conscious processes are those that are experienced at the level of what Schooler (2002) denominates 'phenomenal consciousness' or 'experiential consciousness.' Instead of the latter, this level of consciousness will be termed here ecological consciousness —or, more briefly, consciousness - , but it could be also characterized as environment consciousness, world consciousness, or external consciousness. The reason to call it thus, is that this level of consciousness is mainly oriented toward the integration and experience of environmental stimuli. Ecological consciousness involves the experience of sensory, interoceptive and proprioceptive perceptions, affect, thoughts, and impulses. At this level of consciousness, it is assumed that attention can only be selectively focused on sensory stimuli such as visual and auditory perceptions. This does not mean, however, that internally generated stimuli like thoughts, desires, emotions or sensations do not motivate and direct behavior at this level. They do. It rather means that internally generated stimuli and processes cannot be objects of attention, they cannot be selectively attended to. In sum, internally generated stimuli can be experienced, felt and acted out but they cannot be reflectively accessed and attended to. Factors that seem to induce global states of ecological consciousness in humans include strong emotions and defensive impulses.

Borrowing the terminology of Kross and Ayduk (2017), ecological consciousness is characterized by self-immersion, meaning that organisms exclusively experience events from a first-person perspective: they are completely immersed in —or, as it were, 'fused' with—whatever mental contents are being experienced in the moment. The above implies that animals at this level of consciousness lack introspection of, or reflective access to, their own physical and psychological states. For them, the integrated experience of outer stimuli (sensory perception) and inner stimuli (e.g., interoceptive perception, emotion, thought) is a totality whose constituent elements cannot be selectively accessed or observed. Ecological consciousness can be further characterized as attributive: of instance, if a fruit tastes bad, it is experienced as inherently disgusting; if a predator frightens the organism, it is experienced as inherently threatening. In this way, the appraisals, evaluations and interpretations that organisms make of stimuli are experienced as objective qualities of the stimuli, and not as projections of the particular way of appraising and feeling of the organism.

According to studies about the neural correlates of the emergence of consciousness from general anesthesia, the potential neural substrates of ecological consciousness are phylogenetically ancient structures in the brainstem (locus coeruleus), diencephalon (thalamus and hypothalamus) and the anterior cingulate cortex (Mashour \& Alkire, 2013; see also Merker, 2007). Ecological consciousness may be attributable to organisms such as mammals and birds, whose central nervous systems include at least 
those substrates (Mashour \& Alkire, 2013). (For an account of the possible evolution of consciousness, see Mashour and Alkire (2013), Rial, Nicolau, Gamundí, Akaârir, Garau, \& Esteban (2008), Merker (2007), or Edelman (1992).)

Metaconscious processing and experience. The concept of metaconsciousness (also meta-awareness) proposed by Schooler (2002; Schooler, Mrazek, Baird, \& Winkielman, 2015) will be central to the present theory. Nevertheless, Schooler and his colleagues define it in a way that is significantly different from the definition espoused here. Schooler (2002) conceptualizes metaconsciousness as a thought process by equating it with 'explicit recognition' of experiences, by saying that it 'involves an explicit re-representation of consciousness in which one interprets, describes, or otherwise characterizes the state of one's mind [my emphasis]', or by expressly stating that it is 'a kind of higher-order thought.' Furthermore, Schooler, Mrazek, Baird and Winkielman (2015) consider metaconsciousness 'a kind [...] of conscious experience in which the focus of thought is turned on to itself [my emphasis],' and Chin and Schooler (2009) characterize it as 'one's explicit appraisal of the current content of consciousness.'

DERT's concept of metaconsciousness fundamentally differs from that of Schooler and his colleagues in one important respect. Here metaconsciousness is conceptualized as the reflective access to, and experience of, one's psychological states and processes. It is not a thought process: a mental content—e.g., an emotion—can be metaconsciously experienced and yet not be categorized, recognized, verbalized, interpreted, described, appraised, or self-attributed. Metaconsciousness is a special kind of consciousness that emerges with the advent of self-reflection. Self-reflection allows psychological processes to take other psychological processes as their object (Kihlstrom, Beer, \& Klein, 2003; Lewis, 1990; Oyserman, Elmore, \& Smith, 2012). Thus, metaconsciousness arises with the possibility to direct attention to psychological processes like emotions, thoughts and impulses. Metaconsciousness is therefore oriented toward the reflective experience of, and access to, internally generated stimuli. Internally generated stimuli are metaconsciously experienced whenever they are the objects of attention. Thus, metaconsciousness is a perception-like phenomenon rather than a thought-like phenomenon, and it may be conceived, in a way, as something akin (though not identical) to proprioception or interoception.

The concept of metaconsciousness is related to other concepts like self-consciousness, self-awareness, metacognition, or higher-order thought. These concepts, however, have meanings that are not relevant to the proposed concept of metaconsciousness (Schooler, 2002), and they will be therefore avoided.

As indicated by Schooler, Mrazek, Baird and Winkielman (2015), while the difference between nonconscious and conscious processes is qualitative_-namely that of having or not having subjective experience-, the difference between consciousness and metaconsciousness is quantitative, i.e., of content-with the object of attention being either externally or internally generated stimuli. Schooler (2002) further makes the important distinction that, whereas nonconscious and conscious processing are continuous (during waking state), metaconscious processing is intermittent.

There is a distinctive subjective quality to metaconscious experience. Metaconsciously processed inner stimuli, like emotions or impulses, are experienced and observed as if from a certain distance. These inner stimuli are experienced from a third-person perspective because they are objects of attention. That is to say that the individual is not totally immersed in them. Again, borrowing Kross and Ayduk's (2017) term, the perspective of metaconsciously processed inner stimuli is self-distanced. 
There is a powerful self-regulatory implication to metaconsciousness. At the level of ecological consciousness, internally generated stimuli like thoughts, emotions and impulses are subjects of behavior. At the metaconscious level, however, they become objects of attention and perception. Thus, by being metaconsciously processed, emotions, thoughts and impulses go from being subjects of behavior to becoming potential objects of behavior: more specifically, they become objects of self-regulation.

The concepts of metaconsciousness and self-regulation are two sides of the same coin, namely self-reflection. Metaconsciousness is particularly important for self-regulation because in order to change a particular thought or behavior, they first need to be reflectively experienced (Baumeister, Schmeichel, \& Vohs, 2007). From this point of view, metaconsciousness is a necessary condition for conscious self-regulation. In self-regulation theories, metaconsciousness is often implicit in the concept of 'monitoring,' 'self-monitoring,' or 'self-awareness' (e.g., Baumeister, Heatherton, and Tice, 1994; Baumeister, Schmeichel, \& Vohs, 2007; Carver \& Scheier, 1981, 1998). However, the latter concepts tend to conflate the construct of metaconsciousness with other concepts such as the comparison of actual states with desired states or standards. Hence, these concepts will be avoided in favor of the concept of metaconsciousness.

Metaconsciousness is, of course, phylogenetically much more recent than ecological consciousness (with the latter being a prerequisite for the former), and its potential neural substrate is thought to reside in the prefrontal cortex and in anterior-to-posterior connectivity (Mashour \& Alkire, 2013). One criterion often used to assess whether animals have self-reflection - and, potentially, some measure of metaconsciousness-is the self-recognition mark test developed by Gallup (1970): the animal is marked in a visually inaccessible part of its body and exposed to its own reflection in a mirror; self-recognition is inferred according to the number of mark-directed responses. Animals that pass the test, providing evidence of self-recognition, include chimpanzees, bonobos, orangutans, gorillas, siamangs, gibbons, elephants, dolphins, orcas, and magpies (Mitchell, 2012; Mashour \& Alkire, 2013). In humans, Western children start to develop mark-directed responses-thus providing evidence of self-recognition and passing the test—at the age of 18 to 21 months (ibid.).

Difference between conscious and metaconscious experience. The difference in terms of subjectivity between ecological consciousness and metaconsciousness can be ascertained by asking how a particular psychological process 'feels like' being either outside or inside the focus of attention. To illustrate this difference, it will be useful to consider a few examples of behaviors that are consciously but not metaconsciously experienced. One example are automatic behaviors such as walking or driving a car: when they are carried out with little or no attention, they are experienced faintly (as if they were happening in the background) at the level of ecological consciousness, but not metaconsciously because they were not being objects of attention. In the same line, individuals hardly ever pay attention to their body posture, body movements, gestures and body language, or to their way of speaking (e.g., prosody, melodies, inflections, pet words, etc.). These actions, while unattended, are indeed experienced at some level, but not metaconsciously. For that reason, individuals would typically fail to report many of these behaviors. Yet, an indication that these unattended actions are indeed experienced at some level is that people become gradually metaconscious of them after someone else points them out. Individuals do experience all these processes at some level—i.e., they are not nonconscious—and once attention is focussed on them, they become metaconscious.

Schooler (2002) proposes two alternative examples to illustrate the difference in experience between consciousness and metaconsciousness: mind wandering and emotions. Mind wandering is 
particularly illustrative. When individuals are having a conversation and start thinking about something unrelated, they are mind wandering. When individuals are mind wandering at the level of ecological consciousness, they are engaging and immersed in a chain of faintly conscious thoughts-i.e., they are thinking the thoughts - , not reflectively aware of having those thoughts. Once attention is focused on these thoughts, individuals become meta-aware of them, thus realizing that they are mind wandering-i.e., they are perceiving the thoughts - , and being able to redirect their full attention to the conversation or the reading. Thus, at the level of ecological consciousness, the content of wandering thoughts is being elaborated (i.e., being actively thought) whereas, at the metaconscious level, the process of wandering thoughts becomes the object of attention and is perceived. Regarding emotions, when they are experienced at the level of ecological consciousness, subjects are fully immersed in the emotion, experiencing it from a first-person perspective. At this level, they are not reflectively aware of the emotion: they are certainly experiencing it, feeling it, and possibly acting it out, but the emotion is unattended and hence there is no awareness of the ongoing emotion. In other words, individuals are feeling the emotion and acting it out but they do not explicitly notice it. Even though this idea may seem odd at first, subjects are often immersed in a certain affective state without noticing it until someone tells them that they look sad or angry; then they pay attention to how the are feeling and realize that they are indeed sad or angry. In this way, at the metaconscious level, people are paying attention to their ongoing affective state and thus become aware of it. When metaconsciously experienced, the emotion is no longer experienced from a first-person vantage but from a third-person one: there is a feeling of not being entirely immersed in the emotion, as if there were some distance between self and emotion.

Schooler, Mrazek, Baird, and Winkielman (2015) designed a paradigm of experience sampling of metaconscious versus conscious but not metaconscious mental states. In this paradigm, participants read a text and are intermittently asked whether they are mind-wandering. When they answer that they were indeed mind-wandering, they are subsequently asked whether they had been aware of it prior to being probed. In some occasions, participants answer that they were aware of their mind wandering before being probed (i.e., metaconscious mind-wandering) whereas in some others they inform that they were not aware prior to being probed (i.e., conscious but not metaconscious mind-wandering). They concluded that mind-wandering without metaconsciousness hampered self-regulation (Schooler, Smallwood, Christoff, Handyy, Reichle, \& Sayette, 2011; Schooler, Mrazek, Baird, \& Winkielman, 2015). The same paradigm could be used to assess whether other psychological processes are consciously or metaconsciously experienced (e.g., emotions, impulses, etc.).

Table 3 displays the distinctive characteristics of the three qualitative levels of consciousness.

Table 3. Levels of consciousness and their characteristics.

\begin{tabular}{|l|l|l|l|}
\hline & Nonconscious & Conscious & Metaconscious \\
\hline Attentional focus & None & External, environmental stimuli & $\begin{array}{l}\text { Internal stimuli; psychological } \\
\text { processes }\end{array}$ \\
\hline Perspective & None & $\begin{array}{l}\text { Self-immersed, first-person, } \\
\text { attributive }\end{array}$ & $\begin{array}{l}\text { Metacognitive, reflective, } \\
\text { self-distanced, third-person }\end{array}$ \\
\hline Neural substrate & & $\begin{array}{l}\text { Brainstem (locus coeruleus), } \\
\text { diencephalon (thalamus and }\end{array}$ & $\begin{array}{l}\text { Prefrontal cortex, } \\
\text { anterior-to-posterior }\end{array}$ \\
\hline
\end{tabular}




\begin{tabular}{|l|l|l|l|}
\hline & $\begin{array}{l}\text { hypothalamus), anterior } \\
\text { cingulate cortex }\end{array}$ & connectivity \\
\hline
\end{tabular}

\section{Self-regulatory model}

This section lays out the self-regulatory model that connects the variables of defensiveness, expansiveness and consciousness, and that represents the core of the present theory. Before presenting the model, however, it seems appropriate to consider briefly the concept of self-regulation. Self-regulation emerges with self-reflection and it refers to modifications of the own thoughts, emotions, impulses and behaviors; it can also be conceptualized as the overriding of frequent, dominant, undesired responses and their substitution with less frequent but more desired ones (Baumeister, Heatherton, \& Tice, 1994). Baumeister, Schmeichel, and Vohs (2007) suggest that self-regulation is a human evolutionary adaptation to socialization and culturalization: its function would be to override selfish impulses and to substitute them with more prosocial actions and actions that conform to social standards and expectations, all of which fosters social relationships and group membership, increasing the probability of survival and reproductive fitness.

The process of self-regulation consists of three elements: standards, monitoring, and self-regulatory strength (Baumeister, Schmeichel, \& Vohs, 2007). Standards are the desired responses and psychological states that individuals seek to realize by self-regulating, such as overriding the impulse to smoke a cigarette in order to have a better health, restraining from eating a hamburger and eating a salad instead, seeking positive emotions by entertaining more positive interpretations of events, or 'biting one's tongue' when faced with criticism in order to question oneself. Monitoring involves paying attention to oneself and comparing the current state with the desired state or standard. Self-regulatory strength is the limited resource upon which self-regulatory executive functions like attentional and inhibitory control depend. When the resource is depleted due, for instance, to a demanding, complex task, self-regulatory failure will follow.

DEC space. Before elaborating the self-regulatory model and in order to grasp more easily and graphically the interrelation and dynamics among its three variables, this section introduces the defensiveness, expansiveness and consciousness (DEC) space. DEC space is the three-dimensional vector space spanned by the axes of the three aforementioned variables, as displayed in Figure $2 \mathrm{~A}$. 


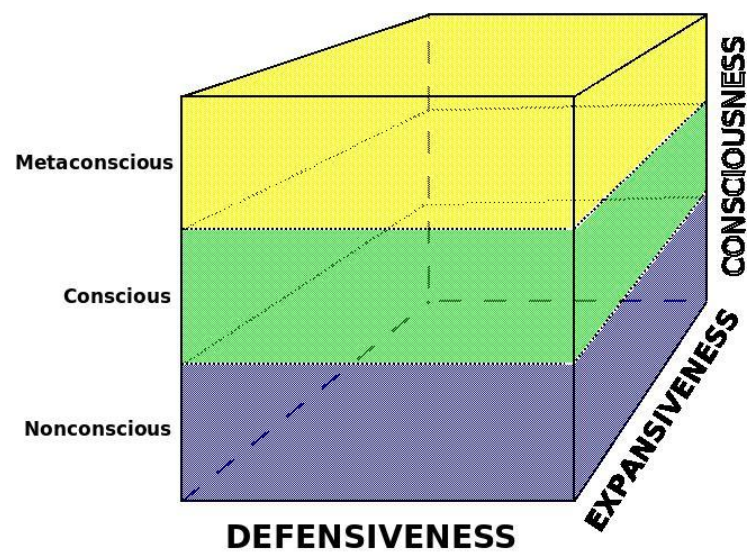

(A)

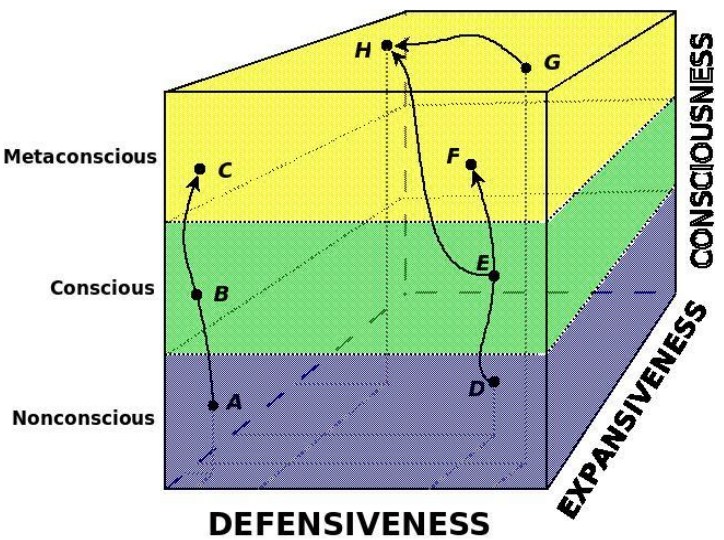

(B)

Figure 2. (A) Representation of DEC space, the three-dimensional vector space spanned by the variables defensiveness, expansiveness and consciousness. The consciousness dimension contains three qualitative levels-nonconscious, conscious and metaconscious-separated by thresholds and each of which has its own continuum. The defensiveness and expansiveness dimensions span the horizontal, motivational plane, which give the measure to which stimuli are evaluated as supporting or thwarting defensive and expansive needs. (B) Trajectories in DEC space, representing possible shifts in the way stimuli are processed and experienced (for a description, see text).

The horizontal plane is spanned by the two motivational variables, defensiveness and expansiveness. A point in this plane informs about the degree of activation of the defensive and expansive system in relation to a particular stimulus. For instance, an unfamiliar street, a stranger, or the thought of death may elicit fear or curiosity, or both. Similarly, we may feel loved by and connected with, or hurt and threatened by a certain person (or both). Points in the motivational plane can also be interpreted in informational processing terms: as the measure to which stimuli are evaluated and processed as thwarting or supporting defensive and expansive needs. Because there are three expansive needs, it may be more useful to think of the expansiveness dimension as representing the one particular expansive need that is relevant to the stimulus and interest in question.

The vertical dimension in DEC space is consciousness. As seen in the previous section, the variable consciousness is made up of three levels: nonconscious, conscious, and metaconscious. Adjacent levels have been assumed to be separated by a threshold. The projection of a point onto the consciousness axis informs about whether the given stimulus is being processed nonconsciously, consciously (i.e, at the level of ecological consciousness), or metaconsciously. Within each level of consciousness there is a continuum, implying that there are some processes that are more or less nonconscious, conscious and metaconscious. The continuums within qualitative levels can be understood in terms of how far given processes are from a given threshold. The conscious and metaconscious levels differ in that psychological stimuli (e.g., thoughts, emotions, impulses) lie outside and inside the focus of attention, respectively.

When motivation - in terms of defensive and expansive needs - and/or consciousness change in relation to a stimulus, these changes describe a path or trajectory in DEC space. The change of state or position in DEC space reflects the shift in the way the stimulus is being processed and experienced (if it is conscious). With regard to the consciousness dimension, trajectories can reflect quantitative changes within a level of consciousness or qualitative changes, that is, jumps from one level to another. In the 
motivational plane, trajectories can be operationalized as changes in the defensive and expansive evaluations of stimuli. The following lines illustrate the concept of DEC trajectories with a few examples. For the first example (see Figure 2B), imagine that point $A$ represents a mannerism (e.g., a particular prosody, use of a pet word, or the waving of one's hands while speaking) that is not accessible to awareness or consciously experienced, and therefore not reportable. In point $B$, the mannerism is consciously but not metaconsciously experienced: it is experienced as if it were in the background of consciousness and it will typically fail to be reported. It is accessible to awareness but it is only faintly experienced because it is not being attended. Finally (point $C$ ), the mannerism is attended and reflectively experienced and can be self-reported.

Alternatively, the trajectory $\mathrm{BC}$ represents the changes in conscious processing of wandering thoughts. In point $\mathrm{B}$, a wandering thought while reading is experienced but unattended (i.e., ecological consciousness), which causes the individual not to realize it and to keep mind wandering. In other words, the individual is fully engaged and immersed in the content of the wandering thought. In point $\mathrm{C}$, however, the individual pays attention to and becomes aware of the wandering thought (i.e., metaconsciousness). This involves that the individual is no longer immersed in the content of the thought but rather observing the mind wandering process as if from a distance. This allows the individual to disengage from the wandering thought and to redirect attention to the reading of the book.

In the case of the trajectory that goes from $D$ to $F$ through $E$, point $D$ represents the nonconscious affective response to a subliminal emotional prime (an angry face, for instance): the prime is strong enough to influence affective physiological processes and behavior but not to generate a conscious emotion (as in Winkielman, Berridge, \& Wilbarger, 2005). In other words, the affective response is nonconscious (if the concept of nonconscious affect seems counterintuitive, see Winkielman, Berridge, \& Sher, 2011; Winkielman \& Berridge, 2004; Winkielman \& Schooler, 2011). In point $E$, the same prime is now strong enough not only to influence physiological affective processes and behavior but also to generate a conscious, though unattended and not metaconscious, emotional experience; when probed, individuals in this state would be able to report the emotion but they would say they were not aware of it before being probed. Finally, in point $F$, the individual directs his or her attention towards the emotion, experiencing it metaconsciously; individuals would be able to report the emotion when probed and would inform of being aware of it prior to being probed.

In the trajectory that goes from $E$ to $H$, point $E$ stands for a worry or feared thought (e.g., the anticipation of failure or rejection). The thought is not reflectively attended but it is rather automatically repeated in the person's mind, reinforcing anxiety. The person is, so to speak, ruminating and fully immersed in the negative thought and its anxiety, and is not aware of this process. This level of consciousness of the feared thought is often accompanied by automatic attempts to escape or suppress it. In point $H$, however, the person is no longer ruminating or attempting to escape or suppress the feared thought but rather receptively and curiously paying attention to it. He or she is not immersed in the content of the thought but directing attention to the process of thought and metaconsciously aware of the fact that it is a thought in his or her mind.

The last example is the trajectory that spans from $G$ to $H$, with point $G$ representing the interoceptive sensation of palpitation or perspiration interpreted by an individual as a symptom of an imminent panic attack, which creates a spiral of anxiety and fear. In other words, the individual is paying attention to a somatic sensation that is being appraised as a threat (i.e., as antecedent of a panick attack). This is a form of defensive metaconsciousness. Defensive metaconsciousness is in evidence whenever the 
attended psychological process (i.e., thought, emotion, etc.) is evaluated as self-threatening or self-supporting. In this example, the stimulus is appraised as self-threatening, which results in anxiety and the impulse to escape or suppress the stimulus in order to avoid the anticipated panic attack. The shift to point $H$, then, represents an evaluative change of the interoceptive sensations as interesting and challenging, which brings about an attitude of openness and curiosity towards them. Of course, this trajectory, as well as the previous ones, can be traversed in the opposite direction (i.e., from $H$ to $G$ ).

\subsection{Model assumptions}

There are a number of assumptions on which the self-regulatory model explicitly or implicitly rests. It will be useful to examine them now before presenting the model.

A1. Competition between defensive and expansive systems. The first assumption refers to the relation between the two psychological systems: the defensive and expansive systems coexist and compete for the control of psychological processes and behavior. Think of a bird that sees a novel stimulus in its cage (e.g., a mirror) and feels curiosity and wants to approach it but at the same time is fearful and wants to avoid it. This motivational conflict between the two systems is pervasive. However, the defensive system tends to dominate whenever a severe threat to life or self is perceived. This is exemplified by a human baby who is playing around or exploring the surroundings and suddenly realizes that her mother has disappeared from view: the most common reaction would be that she would stop playing, and start crying and searching for her mother. Although there are individual differences, security tends to take precedence over expansive pursuits in cases of acute perceived threats. Once a relative measure of security has been restored, expansive pursuits can be optimally attended. In general, which system takes control in any given situation, depends on the relative strength of their activation. When their activation is approximately equal, motivational conflict will ensue. Of course, it is also possible for the two systems to drive in the same direction, as when a student is studying hard because she likes the subject but also to get the best grade among her peers. In sum, DERT assumes that defensive and expansive systems relate to each other in a competitive fashion.

Preliminary evidence for this assumption can be extracted from varied lines of research, such as the coexistence of threat versus challenge appraisals (Lazarus, 1991a, 1991b, 1966; Lazarus \& Folkman, 1984), of distress versus eustress (Le Fevre, Kolt, \& Matheny, 2006; Selye, 1975, 1976), of avoidance versus approach, and more specifically, of performance versus mastery goals (Darnon, Dompnier, Gilliéron, \& Butera, 2010; Barron \& Harackiewicz, 2001; Midgley et al., 1998), of extrinsic versus intrinsic motivations (Ryan \& Deci, 2017), of competition versus cooperation (Deutsch, 2006), of selfish versus prosocial behavior (Baumann, Cialdini, \& Kendrick, 1981; Batson \& Shaw, 1991), or of contingent versus authentic self-esteem (Kernis \& Goldman, 2006; Kernis, 2003). The aforementioned pairs of psychological processes and behaviors - and, potentially, many others - can be interpreted as complementary elements of the competing defensive and expansive systems ${ }^{3}$.

A2. Relation of defensiveness and expansiveness to consciousness. Defensive responses have been naturally selected by conferring organisms with protection against environmental threats, and their efficiency depends on quick activation (Öhman, 2008). In turn, their quick activation depends partly on

\footnotetext{
${ }^{3}$ Note that, ultimately, any given instance of psychological processes and behaviors can only be interpreted as expansive or defensive if they are motivated by expansive and defensive needs, respectively.
} 
automatic, parallel and superficial processing of stimuli (LeDoux, 1996; Öhman, 1986). For this reason, much of the processing of defensive responses is non-conscious (Öhman, 2008; LeDoux, 1996). In line with this, DERT assumes that defensive responses tend to be processed at the lower levels of consciousness, namely nonconsciousness and ecological consciousness. This is not to say that defensive processes cannot be metaconscious: they can, as in the case of defensive self-evaluations, that is, the defensive evaluation of thoughts, emotions, impulses, behaviors or personality traits. However, the assumption here is that defensive responses are predominantly processed at the nonconscious and ecologically conscious levels. In fact, there is evidence for the relation between defensiveness and automaticity: for instance, the personality trait of neuroticism-interpreted here as a relatively general measure of defensiveness_-includes an impulsiveness facet (Costa \& McCrae, 1992). The impulsiveness facet measures uncontrollability, which is one of the qualities of automaticity (Bargh, 1994). The assumption that the defensive system involves more automatic processing and impulsive reactions is consistent with Metcalfe and Mischel's (1999) hot/cool-system analysis, which assumes the existence of a hot system which is emotional, fast, reflexive, and controlled by appetitive and threatening stimuli.

Expansive processes, in turn, involve the exploration, assimilation and mastery of the external and internal reality (Ryan \& Deci, 2017, p. 4; White, 1959, 1963; Piaget, 1952, 1971). The exploration and assimilation of the internal reality require self-reflection, that is, the capacity to take aspects of the self such as thoughts or emotions as objects of attention (Kihlstrom, Beer, \& Klein, 2003; Lewis, 1990; Oyserman, Elmore, \& Smith, 2012). In this context, DERT assumes that the need for competence motivates self-exploration and self-assimilation. This assumption implies that expansive processes are intimately related to self-attention and metaconsciousness. Again, this is not to say that expansive processes cannot occur at nonconscious or ecologically conscious levels. Of course they can, and they do. However, they are, in contrast to defensive responses, assumed to have a characteristic link to metaconscious processing. The self-reflective and metaconscious characteristics of the expansive system are akin to that of Metcalfe and Mischel's (1999) cool system, which is assumed to be reflective and metacognitive (although motivationally ambiguous and, thus, not to be confused with the expansive system).

This assumed differential processing in terms of consciousness and motivation can be represented in DEC space as two distinct hotspots. Hotspots in DEC space are regions with higher frequency of informational processing. The first hotspot will be termed immersed defensiveness (ID) and it has its center in the region of high defensiveness, low expansiveness and ecological consciousness. The name of this hotspot highlights the relevance of defensive over expansive evaluations, as well as the global state of ecological consciousness characteristically induced by defensive processes (recall that self-immersion is a characteristic of ecological consciousness). The second hotspot, which will be termed introspective expansiveness (IE), has its center in the region of low defensiveness, high expansiveness and metaconsciousness (or, at least, higher in the vertical axes than the ID hotspot). The denomination of the IE hotspot underscores the relevance of expansive over defensive evaluations, as well as the metaconsciousness that is motivated by expansive pursuits such as self-exploration or curiosity. For illustrative purposes only, Figures 3A and 3B display the two hotspots in DEC space in the form of density plots, with blue colors indicating lower activity and red colors higher activity. Blue colors do not mean absence of activity but rather comparatively lower activity. 


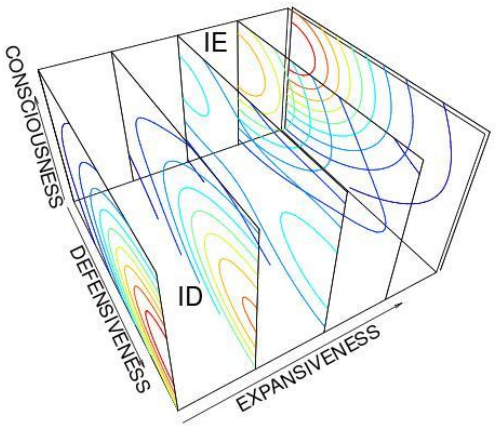

(A)

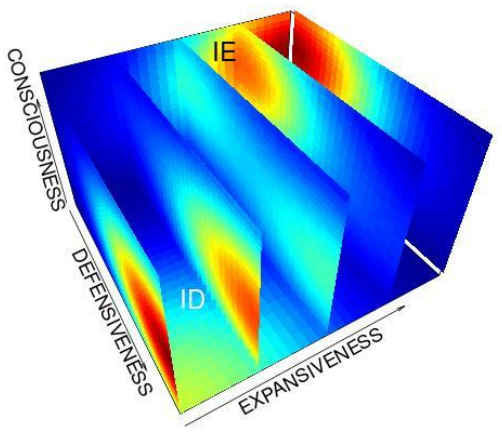

(B)

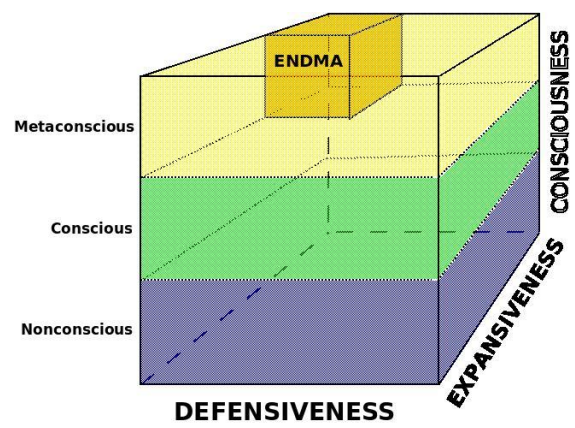

(C)

Figure 3. Illustration of the two hotspots assumed to exist in DEC space (see Assumption 2). The different colors stand for different frequencies of activation, with blue colors indicating lower frequencies and red colors higher frequencies. Slices of DEC space with (A) isolines, that is, contour lines with constant frequency of activation, and (B) continuous surfaces. The acronyms ID (immersed defensiveness) and IE (introspective expansiveness) mark the location of each hotspot. (C) Region of expansive, non-defensive meta-awareness (ENDMA) in DEC space.

From a self-regulatory point of view, a region of special significance in DEC space-and which is part of the IE hotspot-is that of expansive, non-defensive meta-awareness (ENDMA), which involves a type of processing and experience characterized by low defensiveness, high expansiveness, and high metaconsciousness. Figure 3C represents the region of ENDMA within DEC space. States of ENDMA are those in which individuals focus their attention upon their own psychological states and processes with an open-minded and curious attitude, and without defensively evaluating them or trying to escape awareness of them. The way in which inner stimuli are processed and experienced from an ENDMA perspective has been illustrated above in point $H$ of Figure 2B (see text).

Four concepts in the extant literature relate intimately to ENDMA: emotional intelligence, internal state awareness, mindfulness, and exposure. Emotional intelligence (EI) refers to the capacity to perceive, assimilate, understand and regulate emotions to promote growth (Mayer, Salovey, \& Caruso, 2004), all of which are also potential facets of ENDMA. However, there are, at least, four important differences between the two constructs: (a) EI's object is restricted to emotion whereas that of ENDMA includes all possible psychological processes, namely sensation, perception, emotion, cognition, impulse and behavior, which makes ENDMA a broader concept; (b) EI can include other's emotions while ENDMA's objects are always intrapsychological; (c) the concept and measurement of EI has a more cognitive emphasis (e.g., identification, reasoning) whereas ENDMA's is more perceptive; and (d) the concept of EI is motivationally ambiguous while ENDMA's is not. Internal state awareness (ISA) is a factor of the Private Self-Consciousness subscale (Watson, Morris, Ramsey, Hickman, \& Waddel, 1996) which is composed of four items (e.g., "I'm generally attentive to my inner feelings.", "I'm alert to changes in my mood."). ISA and ENDMA have in common self-directed attention and metaconsciousness. However, ISA's items are motivationally ambiguous, which makes it a rather pure measure of metaconsciousness. In contrast, ENDMA is a motivationally specific type of metaconsciousness. Mindfulness has been defined in a multiplicity of ways (Quaglia, Brown, Lindsay, Creswell, \& Goodman, 2015) and it basically refers to "paying attention in a particular way: on purpose, 
in the present moment, and nonjudgmentally" (Kabat-Zinn, 1994). Due to the multiplicity of definitions of mindfulness it is difficult (or impossible) to make a definitive comparison between that concept and ENDMA. However, the two concepts have in common the centrality of (a) self-directed attention and (b) a particular attitude often characterized as nonjudgmental, kind and curious in the context of mindfulness versus a particular motivation characterized as low defensiveness and high expansiveness in the context of ENDMA. Yet, at least three important differences between the two concepts can be pointed out: (a) the object of mindful attention can include both environmental and psychological stimuli whereas that of ENDMA can include, by definition, only psychological stimuli; (b) mindful attention is framed within a set of attitudes (e.g., openness, acceptance, kindness, curiosity) while ENDMA is framed within a set of fundamental motivations; what is more, the concept of ENDMA — and DERT's evolutionary and motivational framework - can accommodate and explain mindful attitudes as particular facets of low defensiveness (e.g., nonjudgmental) and high expansiveness (e.g., curiosity, openness); and (c) the concept of mindfulness originates from Buddhist philosophy whereas that of ENDMA is derived from secular, established psychological constructs. Intriguingly, recent research suggests that increases in ENDMA-type states and traits-measured as mindfulness - can be chemically induced by intake of psychoactive substances such as psilocybin (Madsen et al., 2020) or ayahuasca (Sampedro et al., 2017; Soler et al., 2016). The fourth concept, exposure, was developed in the context of exposure therapy for the treatment of anxiety disorders and involves the repeated and systematic confrontation of feared stimuli (Moscovitch, Antony, \& Swinson, 2009). Like ENDMA, exposure requires (a) the inhibition of 'safety behaviors' such as avoidance of or distraction from the feared stimulus (i.e., non-defensive) and (b) attention to the emotions, cognitions and behaviors elicited by the feared stimulus (i.e., metaconscious). Despite these similarities, the two concepts differ in: (a) their level of generality, with exposure applying exclusively to the regulation of anxiety disorders, and ENDMA, more generally, to the regulation of both defensive and non-defensive processes, pathological or not; as for defensiveness, ENDMA is not restricted to the regulation of anxiety but also to that of all other defensive manifestations (see Table 2); and (b) that, unlike ENDMA, exposure is not formulated within a fundamental theory of human motivation, which makes it motivationally ambiguous.

A3. Defensiveness fragments the self, ENDMA integrates it. DERT assumes that the internalization of and conformity to cultural values, norms and standards is a crucial adaptation to life in a group setting that confers individuals with distinctive benefits, such as group protection, resources, knowledge or skills. It is further assumed here that this internalization and conformity are part of the default activity of the defensive system. On the other hand, DERT also assumes that this internalization has costs in terms of being a potential source of psychological fragmentation and distress in the form of defensive self-evaluations and judgments, self-evaluative emotions, inadequacy and contingent self-esteem. Evidence for this assumption can be found in the research that shows that the empirical trait of neuroticism — which, again, is interpreted here as a relatively general measure of

defensiveness-includes a self-consciousness facet, which measures inadequacy, inferiority and self-evaluative emotions like guilt and embarrassment (Costa \& McCrae, 1992). Other studies have found that neuroticism or emotional instability predict both guilt and shame (Abe, 2004, Table 1; Einstein \& Lanning, 1998, Table 2) and self-esteem contingency (Sowislo, Orth, \& Meier, 2014, Table 1; Zeigler-Hill, Clark, \& Pickard, 2008, Table 1).

Further, it is postulated here that ENDMA brings about the reappraisal, extinction and/or reconsolidation of defensive evaluations, in general, and of defensive self-evaluations, in particular. In 
other words, ENDMA is assumed to down-regulate defensive self-evaluations and fragmentation. This down-regulation of defensive self-evaluations results in a more integrated self. These underlying mechanisms of ENDMA have also been proposed as the explanation of the self-regulatory effects of mindfulness (Hölzel et al., 2011). Supporting evidence for this assumption stems from studies showing correlations between ENDMA-related concepts (i.e., internal state awareness, mindfulness, emotional intelligence) and defensive self-evaluations: (a) internal state awareness correlates negatively with guilt and shame (Watson et al., 1996, Table 2) and with depression (Reeves, Watson, Ramsey, \& Morris, 1995, Table 2); (b) mindfulness correlates negatively with self-criticism, inadequacy and self-hate (Cunha \& Paiva, 2012, Table 3), guilt (Friese \& Hofmann, 2016), shame (Woods \& Proeve, 2014, Table 1), and depression and the self-consciousness facet of neuroticism (Brown \& Ryan, 2003, Table 4); (c) emotional intelligence correlates negatively with depression (Mikolajczak, Luminet, \& Menil, 2006) and shame (Mikolajczak, Nelis, Hansenne, \& Quoidbach, 2008, Table 2).

\section{A4. ENDMA, and not defensiveness, is the long-term, adaptive response to self-threats.}

Evolutionary cost-benefit analysis posits that behavioral adaptations have both benefits and costs in terms of reproductive fitness and that, for a behavior to be considered as adaptive, its benefits must exceed its costs (Ha, 2010). Following this logic, DERT assumes that defensive behaviors and processes have both benefits and costs, and that their benefits exceed their costs in terms of reproductive fitness. With the evolutionary emergence of self-reflection, there is a considerable increase in terms of the benefits of defensiveness (e.g., anticipation of, and adaptation to, future threats) but also in terms of its costs (e.g., unnecessary and counterproductive worries and ruminations). It is postulated here that optimal self-regulation requires the simultaneous maximization of the benefits and minimization of the costs associated with reflective defensiveness. If reflective defensiveness is not optimally regulated, it can result in unnecessary and counterproductive stress, anxiety, interpersonal and intergroup conflict, etc. Some of the costs of defensiveness are reflected by meta-analytic evidence of moderate to strong correlations between neuroticism and negative affect (Anglim, Horwood, Smillie, Marrero, \& Wood, 2020, Table 4) and of positive correlations between neuroticism and potentially maladaptive forms of self-regulation — such as avoidance, suppression of thoughts and emotions, worry, rumination, denial, wishful thinking, or substance use - as well as negative correlations between neuroticism and adaptive forms of self-regulation-e.g., problem solving, reappraisal, acceptance, or mindfulness (Barańczuk, 2019, Table 1; Connor-Smith, \& Flachsbart, 2007, Table 7); additionally, neuroticism has been linked to less flexibility in the use of self-regulatory strategies (Lee-Baggley, Preece, \& DeLongis, 2005).

Minimizing the cost of reflective defensiveness involves the down-regulation of defensive responses. DERT assumes that this cannot be achieved by performing self-protective behaviors, such as escape, avoidance or aggression, because this would maintain the underlying self-threatening evaluations; instead, what is required for the down-regulation of defensive responses is a new evaluation of relative security of the threatening stimuli, which is achieved by exposure and ENDMA. The first part of this assumption is supported by evidence showing that aggression and venting anger maintain and increase subsequent anger and aggression (Bushman, 2002) or that other self-protective behaviors, such as avoidance, maintain or exacerbate anxiety (Helbig-Lang \& Petermann, 2010). The second part of this assumption is supported by another line of behavioral and neurological evidence that shows that (a) fear conditioning and extinction are coexisting memories with distinct amygdala networks (Duvarci \& Pare, 2014), and (b) fear memories can be reconsolidated, that is, modified or erased after being retrieved and updated with fear-incompatible information (Nader \& Einarsson, 2010). Finally, this assumption is 
consistent with emotional processing theory (Foa, Huppert, \& Cahill, 2006), which posits that the extinction of fear responses involves the activation of the existing fear structure and the encoding of information about the relative security of the stimulus, which coexists and is incompatible with the existing fear structure.

A5. Defensiveness is a main cause of distress, and expansiveness of well-being. As stated above, the defensive system is an evolutionary adaptation that serves to detect and reduce threats. Thus, its very function intimately ties defensiveness to negative events and emotions. Compared to positive defensive affect (e.g., peace, security), negative defensive affect (e.g., fear, anxiety, anger, etc.) bears a more acute meaning for self-preservation, namely the presence of a threat to life or self. The present theory assumes that natural selection favored organisms with a specific defensive bias: the existence of a lower threshold for threat appraisals than for support appraisals, as well as stronger affective, cognitive and behavioral responses to threatening than to supporting stimuli. Evidence for this assumption stems from the negativity bias (Larsen \& Prizmic, 2008), the law of hedonic asymmetry (Frijda, 1988; 2007) and affective, cognitive and behavioral asymmetries (Cacioppo, Berntson, Norris, \& Gollan, 2012; Cacioppo, Larsen, Smith \& Berntson, 2004; Baumeister, Bratslavsky, Finkenauer, \& Vohs, 2001; Taylor, 1991). This asymmetry constitutes at the same time a benefit (in terms of survival) and a cost (in terms of well-being). Further, and consistent with self-determination theory (Ryan \& Deci, 2017, p. 255), DERT posits that the need for security and defensiveness have more to do with negative events and emotions and their down-regulation than with positive events and emotions and their up-regulation. Preliminary evidence for this postulate can be found in a recent meta-analysis of personality and well-being: neuroticism has a significantly stronger correlation with negative affect (.56) than it does with positive affect and life satisfaction (-.34 and -.39, respectively) ${ }^{4}$ (Anglim et al., 2020, Table 4).

The expansive system, in turn, has a more developmental function, intrinsically motivating behaviors such as exploration, play, pursuit of novelty and challenges, social interactions and relationships, etc. Hence, the expansive system, when compared with the defensive system, has a stronger relationship with positive events and emotions and their up-regulation. In relation to this assumption, several meta-analytic studies have found that expansive needs have a stronger correlation with positive than with negative affect (Stanley, Schutte, \& Phillips, 2020; Teixeira, Marques, \& Palmeira, 2018, Table 2; van den Broeck, Ferris, Chang, \& Rosen, 2016, Table 5; Ng et al., 2012, Table 2), yet at least one has not found this pattern of results (Anglim et al., 2020, Table 10). Note that this empirical affective asymmetry is opposite to that found for defensiveness.

A6. Hedonic nexus between expansiveness and defensiveness. As indicated already, experiences of pain and pleasure lead to negative and positive defensive evaluations, respectively. This is assumed to be a general evolutionary adaptation that causes organisms to avoid stimuli and environments previously associated with pain and harm and to approach those associated with pleasure and security. This general adaptation translates into a more specific hedonic nexus between the expansive and defensive systems: the satisfaction and frustration of expansive needs leads to respective positive and negative defensive evaluations of the stimuli and environments associated with the aforementioned satisfaction and

\footnotetext{
${ }^{4}$ It should be noted, though, that this result might be a methodological artifact, given that (a) most of the studies used in the meta-analysis used the Positive and Negative Affect Schedule (PANAS; Watson, Clark, \& Tellegen, 1988) or a variant of the PANAS to measure positive and negative affect, and (b) the PANAS positive scale appears to measure positive expansive affect whereas the PANAS negative scale seems to measure negative defensive affect.
} 
frustration. Evidence for this assumption can be extracted from meta-analyses showing low to moderate positive correlations between neuroticism and expansive needs (Anglim et al., 2020, Table 4; van den Broeck et al., 2016, Table 2).

It is further assumed here that the internalization of and conformity to in-group (or aspired group) norms, values and beliefs is a defensive adaptation that increases the probability of survival and reproductive fitness by facilitating the group's acceptance and protection. By means of the hedonic nexus, the frustration of expansive needs would lead, more specifically, to (defensive) negative self-evaluations and the adoption and pursuit of social standards of value, such as wealth, materialism, power, recognition, fame, status or image. A plethora of empirical studies show that frustration of expansive needs is associated with the adoption of such defensive, compensatory goals (Ryan \& Deci, 2017, Chapter 11). For instance, a recent meta-analysis on materialism and well-being showed that the frustration of expansive needs is positively correlated with materialistic values and goals (Dittmar, Bond, Hurst, \& Kasser, 2014, Table 12).

\subsection{Defensive versus expansive self-regulation}

The self-regulatory model introduced in this section is a synthesis of the basic concepts presented so far. The model connects the concepts of defensiveness, expansiveness and consciousness in two distinct self-regulatory modes that are conducive either to fragmentation and distress or to integration and well-being. These two modes refer to defensive and expansive self-regulation (henceforth, self-regulation will be referred to as "regulation"). Defensive regulation is the totality of overt and covert psychological and behavioral processes seeking to down-regulate perceived self-threats and motivated by the need for security. The previous definition includes all defensive appraisals, emotions, behaviors and attitudes. Defensive regulation seeks to maximize and restore security. Expansive regulation, in turn, involves expansive, non-defensive meta-awareness (ENDMA) of the own psychological states and processes. This second type of self-regulation is motivated by expansive needs, especially by competence, which drives self-exploration, self-questioning and metacognitive learning. In the context of perceived self-threats, expansive regulation holds the potential to restore psychological security: not by means of self-protection, however, but by means of metaconsciousness of the psychological processes giving rise to self-threats, such as defensive evaluations, interpretations and identifications.

This model has been built around the premise that, compared to defensive regulation, ENDMA is the long-term, more adaptive mode of self-regulation wherever perceived self-threats and subsequent defensive responses arise. The import of ENDMA is precisely its capacity to down-regulate self-threats and defensive responses and, thus, to restore psychological security. Defensive responses encompass all the thoughts, emotions, impulses, perceptions, or actions motivated by perceived self-threats and the need for psychological security. Whether one feels inadequate, offended or humiliated by one's boss, fearful of losing one's job or of a potential relationship breakup, anxious about how one may be perceived by others, or threatened by someone else's competence or success, the adaptive way to regulate such thoughts and emotions is assumed here to be ENDMA. Let us see what that entails. Operationally, ENDMA is defined in the present context as inhibition of defensive responses and open, inquisitive self-directed attention. The term 'self-directed attention' refers to paying attention to the own mental contents, that is, to one's psychological reactions, states and processes. Qualifying self-attention as 'open' and 'inquisitive' implies that it is motivated by the need for competence, by the desire to learn about, and assimilate, the attended 
stimulus. In turn, the inhibition of defensive responses alludes to the effortful override or suspension of all the responses that are motivated by the need for psychological security, especially the avoidance of the perceived self-threat and its defensive evaluation (i.e., as good or bad, desirable or undesirable); more simply put, it means that one restrains oneself from being dragged by, or immersed in, automatic defensive reactions.

The above operational definition of ENDMA indicates that it is a higher-order executive function. It relies heavily on many basic executive functions such as inhibitory control (of defensive responses), attentional control (to direct attention towards inner instead of outer stimuli), cognitive inhibition (to ward off distractions), and working memory (to remember the goal, and monitor the process, of inhibiting defensive responses and paying self-directed attention), as well as higher-order executive functions like fluid intelligence (e.g., to identify new forms of defensive responses).

To illustrate the two modes of self-regulation, let us begin by considering Figure 3A. The first route, that of defensive regulation, starts with a stimulus. When the stimulus is evaluated as a self-threat (right arrow), the defensive system is activated, and the default response will be defensive (arrow that goes from self-threat to self-protection). When the perceived self-threat is an outer stimulus (e.g., a disliked person, negative information about the self, someone with more success than oneself, an environmental cue associated with negative past experiences, a transgression of social norms or values), the typical defensive responses are avoidance, escape or aggression. When the self-threat is an inner stimulus (e.g., the anticipation of a rejection or failure, self-disconfirming or negative thoughts about the self, negative emotions like loneliness or fear, morally incongruent impulses), typical defensive responses range from escaping awareness of the stimulus and distraction to its suppression. As said before, this route from the appraisal of the stimulus as self-threatening to a defensive response (i.e., self-protection) is the default. The activation of this route, that is, responding defensively to a perceived self-threat, is assumed to maintain defensive evaluations, deepen fragmentation and cause distress. Hence, this defensive self-regulatory route, albeit being the default, is maladaptive as long-term strategy. The second route represents expansive regulation and also spans from the stimulus to the self-threat, meaning that initially the stimulus is processed and evaluated as a self-threat-as in the first route. However, in this case the response to the self-threat is not defensive (i.e., self-protection) but ENDMA. This expansive response to a self-threat is arguably less frequent than the previous defensive response. The expansive response to a self-threat implies that the stimulus is being simultaneously appraised as a threat (i.e., defensive evaluation) and as a challenge, a novelty or a curiosity (i.e., expansive evaluation). Hence it entails a motivational conflict, with the defensive system motivating the avoidance of the stimulus and the expansive system motivating its approach.

Sometimes the response of ENDMA to self-threats happens spontaneously and effortlessly, that is, as a bottom-up process. Yet, it may also happen as a top-down process: with the individual explicitly reminding himself or herself not to respond defensively and to pay attention to his or her psychological state and responses with an inquisitive open mind. In the context of self-threats, the object of ENDMA are the own psychological state and responses to the threat, namely one's perceptions, evaluations, interpretations, emotions, motivations and impulses in connection with the threat. In other words, its object are the own defensive responses to the threat. 


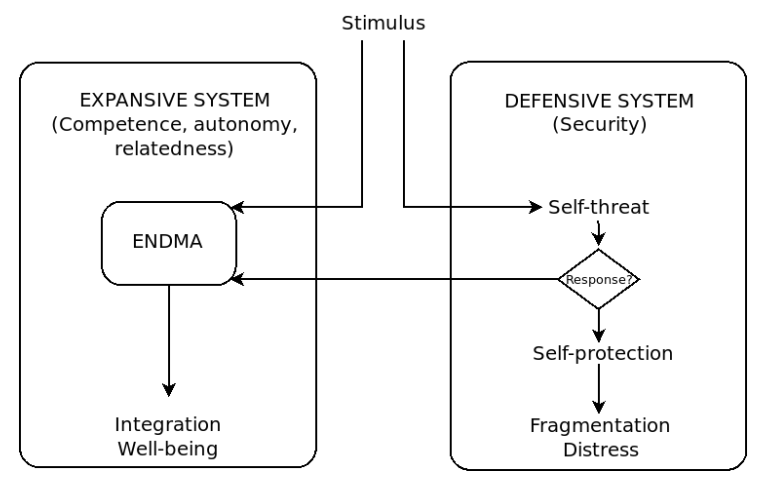

(A)

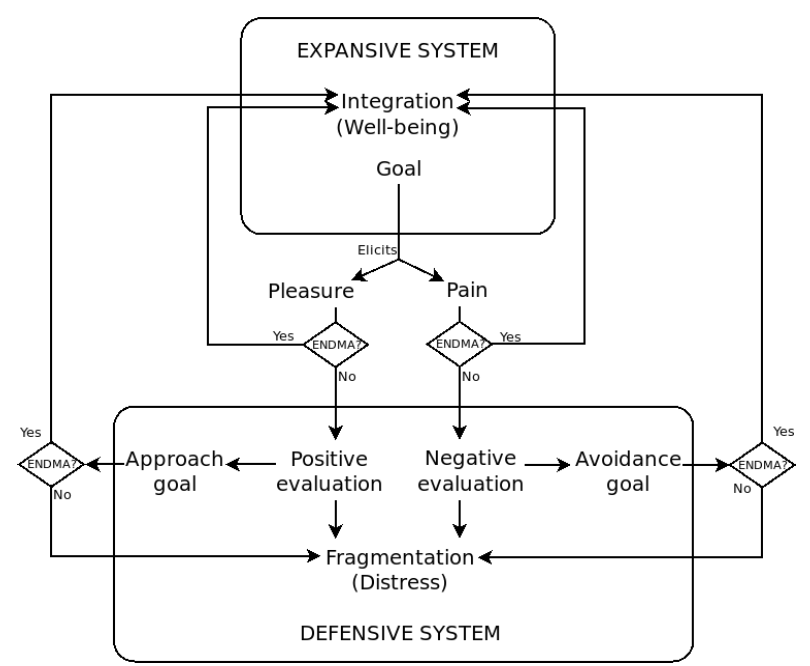

(B)

Figure 4. Models of defensive and expansive self-regulation. (A) Self-regulatory model displaying the two types of response to perceived self-threats: a defensive route (stimulus $\rightarrow$ self-threat appraisal $\rightarrow$ self-protection $\rightarrow$ Fragmentation $\rightarrow$ Distress) leading to fragmentation and distress, and an expansive route (stimulus $\rightarrow$ self-threat appraisal $\rightarrow$ ENDMA $\rightarrow$ Integration $\rightarrow$ Well-being) leading to integration and well-being. A third route (stimulus $\rightarrow$ ENDMA) represents the meta-awareness of mental contents that lack defensive relevance (see text for a description). (B) Hedonic nexus between expansive and defensive systems (for a description, see text).

Let us now illustrate the two self-regulatory routes in Figure 4A with examples to clarify their difference. The first route, representing defensive regulation (stimulus $\rightarrow$ self-threat appraisal $\rightarrow$ self-protection), can be illustrated by the following situations and responses: when individuals are publicly criticized, they typically feel threatened and react aggressively; when people compare themselves with someone who surpasses them regarding a valued trait (e.g., success, intelligence, attractiveness, popularity), they tend to feel inferior and threatened, and to defend themselves by cognitively restructuring the situation, for instance, by giving less value to the trait or by seeking for faults in the other person; when people's security-providing beliefs (e.g., cultural, political, religious, etc.) are questioned, they deflect the question and turn aggressive; when they recall negative events of their past or when they anticipate negative outcomes (e.g., of loss, rejection or failure), they feel anxious and suppress the troubling thought. Let us now turn to some examples of the second route, representing expansive regulation in the form of ENDMA as a response to self-threats (stimulus $\rightarrow$ self-threat appraisal $\rightarrow$ ENDMA). One example in which the perceived self-threat is external to the self, is the fear of speaking in public. The fictional first-person scenario presented in Box 1 illustrates this case.

Box 1. Fictional first-person account illustrating expansive regulation of self-threat that is external to the self. 


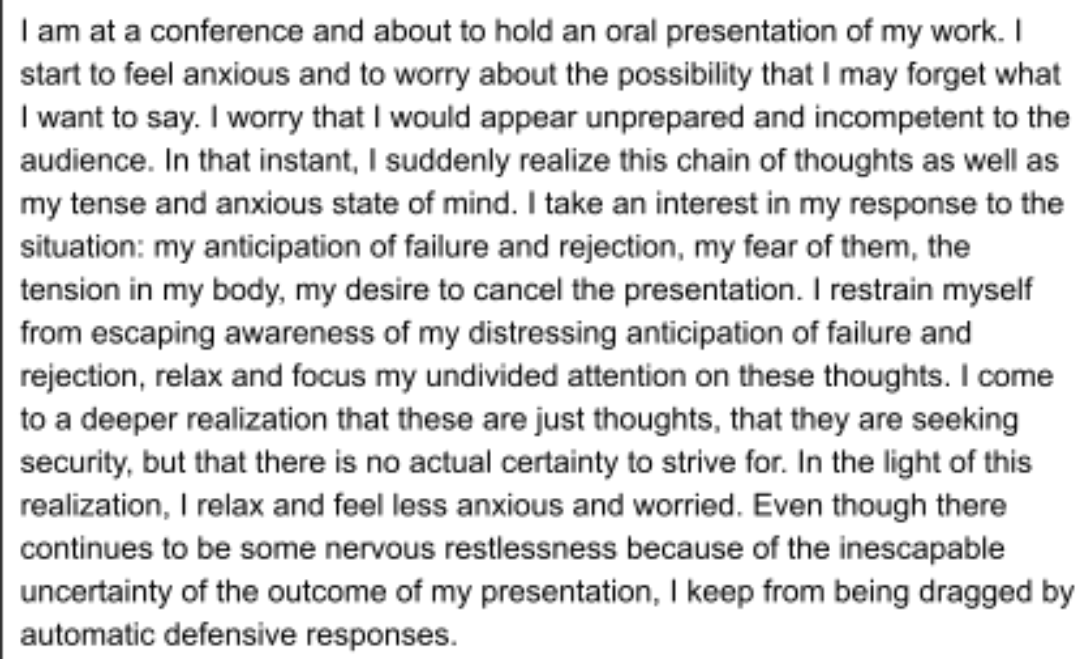

Box 2 presents an additional fictional account that illustrates a perceived self-threat that is internal to the self, namely thoughts of inadequacy or negative self-evaluations.

Box 2. Fictional first-person account illustrating expansive regulation of self-threat that is internal to the self.

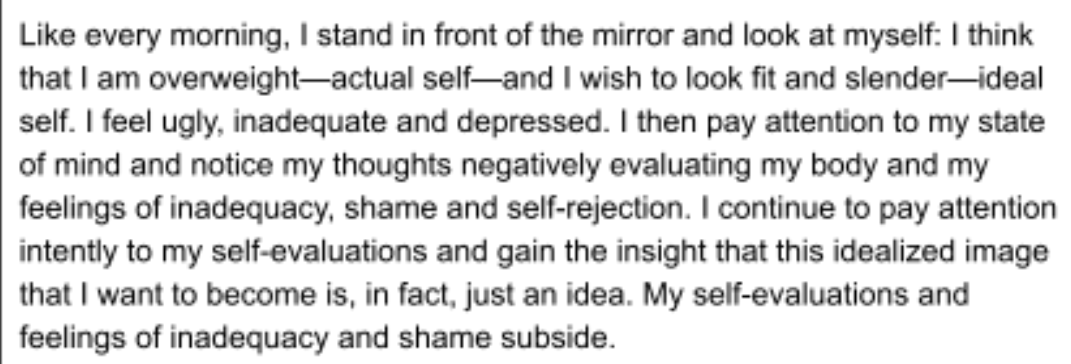

An additional and final example that illustrates the expansive regulation of self-threats that are internal to the self is presented by Box 3 .

Box 3. Fictional first-person account illustrating expansive regulation of self-threat that is internal to the self. 


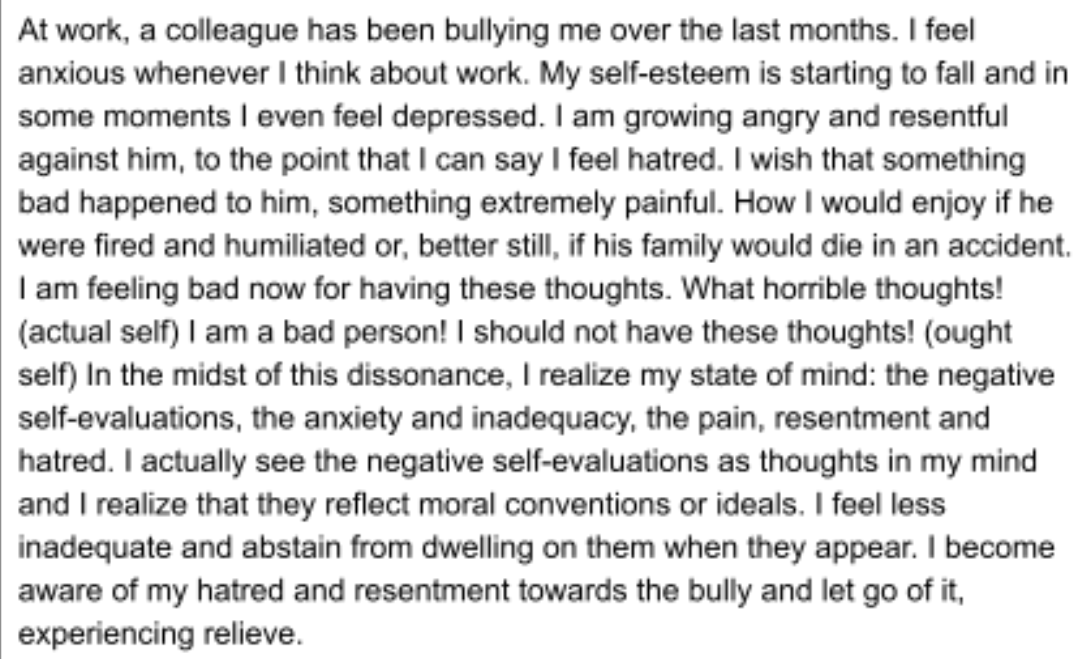

The previous examples of ENDMA as a response to self-threats can be represented by the trajectory that spans from point $E$ to point $H$ in DEC space (see Figure 2B): initially, the stimulus is solely defensively evaluated as a threat and experienced at the level of ecological consciousness; gradually, the own psychological reactions to the stimulus are metaconsciously experienced and defensive evaluations are down-regulated in favor of expansive evaluations (e.g., interest, challenge, curiosity). Thus, expansive regulation restores psychological security by down-regulating threat appraisals and up-regulating expansive appraisals. This process often involves metaconsciousness, exploration and questioning of one's important identities, assumptions, standards, beliefs, values and goals.

The aforementioned examples illustrate the difference between defensive regulation-i.e., self-protection - and expansive regulation-i.e., ENDMA — of self-threats, as well as the benefits of the latter in comparison with the former: the down-regulation of negative emotions, self-evaluations and, more generally, of defensive appraisals and responses.

Expansive regulation may seem akin to general self-regulatory strategies such as cognitive change and reappraisal, as studied by other authors (e.g., Gross, 2014). However, such concepts are fundamentally different from ENDMA in that: (a) they are motivationally ambiguous, that is, they can be motivated by both defensive and expansive needs; (b) they are ambivalent as to the level of consciousness (i.e., ecological or metaconscious), taking both external and internal stimuli as their object; and (c) they are mainly cognitive processes whereas ENDMA is a perceptive process. Cognitive change and reappraisal can result from expansive regulation but the two concepts ought not to be confused.

Metaconsciousness is the basis of self-regulation and, more specifically, of psychotherapy: after all, it is hardly possible to change a behavior if one is not aware of it (Baumeister, Schmeichel, \& Vohs, 2007). The assumed self-regulatory and therapeutic effects of ENDMA can be partly attributed to reappraisal. This is consistent with many therapeutic approaches. Cognitive-behavioral therapies (CBTs), for instance, rely on metaconsciousness to access, identify and modify dysfunctional beliefs, which, in turn, changes behavior (Dozois, Dobson, \& Rnic, 2019): first- and second-generation CBTs emphasize direct behavioral and cognitive change, respectively, whereas third-generation CBTs emphasize the recognition and acceptance of metacognitive processes. ENDMA's emphasis is more consistent with the latter than it is with the former, as there are two important differences in focus between standard CBTs 
(i.e., rational emotive therapy and cognitive therapy) and ENDMA: (a) standard CBTs have a cognitive and verbal emphasis whereas ENDMA has a perceptive and non-verbal emphasis; and (b) standard CBTs focus on cognitions whereas ENDMA indistinctly focuses on any kind of content, especially of defensive nature (cognitions, affect, impulses, behaviors, etc.). In sum, the concept of ENDMA is not concerned with exerting direct changes in the contents of particular beliefs and behaviors but, rather, with becoming non-defensively and non-verbally aware of one's thoughts, emotions, perceptions and impulses. Contingently, this awareness can lead to changes in the contents of particular appraisals, beliefs, assumptions, expectations, attributions, attitudes, behaviors, and so on.

There is a third and last route depicted in Figure 4A which represents expansive regulation of mental contents lacking defensive relevance: it goes directly from the stimulus to ENDMA (stimulus $\rightarrow$ ENDMA). As implied by this route, the stimulus is not appraised as a self-threat at any time. This route stands for the expansive appraisal—as curiosity, challenge or novelty — and metaconsciousness of such stimuli, which encompass one's psychological states, responses, and processes. The self-regulatory relevance of this route can be illustrated by the perception of a bodily tension and its subsequent release, the observation of a bad bodily posture and its correction, the observation of the impulse to overeat (while in a diet) and its inhibition, or the perception of a wrong assumption or interpretation and its subsequent suspension and modification.

Figure 4B shows the hedonic nexus between the expansive and defensive systems. Expansive needs set in motion goals and actions intended to satisfy them. When those goals are achieved, satisfying expansive needs, they generate well-being and pleasure. Conversely, when those goals are not achieved, they generate ill-being and pain. If there is no ENDMA of the pain or pleasure, the typical consequence is the formation of negative or positive defensive evaluations, respectively, of the need-thwarting or need-supporting stimulus, goal, or activity. In this way, the pain or pleasure derived from the frustration versus satisfaction of expansive needs can link to the formation or maintenance of defensive appraisals, goals and responses. The latter results, as we saw earlier, in fragmentation and distress. In contrast, when the response to the pain or pleasure derived from the frustration or satisfaction of expansive needs is ENDMA, the latter inhibits the formation of new, or reconsolidation of existing, defensive evaluations. This leads to integration and well-being. For example, if one is rejected by a person one just tried to approach (thwarting relatedness), one will likely evaluate him or her negatively and be deterred from similar attempts in the future, unless one responds to the pain of rejection and the negative evaluations with ENDMA. Let us now think of a student who, after spending a lot of time and effort trying to learn and master a particular subject, repeatedly fails to pass the final exam (thwarting competence): the mounting feelings of frustration, anger and incompetence would typically result in negative evaluations of the subject or the teacher. If the student is non-defensively metaconscious of her pain and her negative evaluations, only then will the latter not be recorded or reconsolidated in her memory. Imagine now a father who frequently invalidates and restricts his son's responses, actions and choices (thwarting autonomy): the son will feel insecure, resentful and angry at his father, and will negatively evaluate him. Again, in the presence of ENDMA of the anger and the defensive appraisal, the latter does not get recorded or reconsolidated in memory. Corresponding examples can be given for cases in which the satisfaction of expansive needs and the subsequent pleasure and well-being lead to positive defensive evaluations. In sum, expansive regulation in form of ENDMA of the pain or pleasure following the frustration or satisfaction of expansive needs inhibits the formation or reconsolidation of defensive appraisals. This inhibition can be either partial or complete. Evolutionarily, the adaptive value of this 
hedonic nexus between expansive and defensive systems is clear: it promotes (or prevents) the approach of stimuli that foster (or thwart) development. This link, however, may be modulated by the pre-existing degree of satisfaction of expansive needs, and by other factors.

As can be seen in Figure 4B, positive and negative defensive appraisals generate approach and avoidance goals, respectively. These defensive goals are automatically activated once the evaluated stimulus is perceived. When these goals are automatically activated and acted upon, they and their corresponding defensive appraisals are reconsolidated in memory, and promote fragmentation and distress. However, when they are non-defensively and metaconsciously experienced (i.e., in terms of ENDMA), their reconsolidation is inhibited, fostering integration and well-being.

The hedonic nexus between the expansive and defensive systems can also result in the formation of compensatory defensive goals, namely security-driven goals whose psychological function is to compensate for the frustration of an expansive need. By way of illustration, consider again the boy whose father frequently invalidates his responses and restricts his choices: the boy's need for autonomy would be severely frustrated. The common defensive reaction to this frustration of autonomy would be reactance, the angry and resentful rebellion against the coercion of the father in order to restore his perception of freedom and choice. Similarly, the frustration of relatedness can lead to compensatory defensive goals like status, popularity, fame, recognition or reputation. On the other hand, the frustration of competence can result in defensive goals such as power, domination, or wealth.

The self-regulatory model that I have presented here is based on the distinction between defensive and expansive regulation. Expansive regulation in the form of ENDMA is a way of processing experiences characterized by reflective attention to, and awareness of, one's psychological state, processes and responses, with an open and inquisitive attitude. The two most important assumptions of the model are: (a) that, in the context of self-threats, ENDMA down-regulates defensive responses in general (including anxiety, fear, avoidance, etc.) and defensive appraisals in particular, restoring psychological security and promoting psychological integration and well-being; and (b) that ENDMA can regulate psychological processes and mental contents in general, such as emotions, thoughts, interpretations, assumptions, evaluations, attitudes, impulses and behaviors. Many of the psychological, social, political, economic and environmental problems originate from the way people interpret and evaluate themselves, others and the world; and it is only by paying attention to, and being non-defensively aware of, those interpretations and evaluations that those problems may be solved.

\subsection{Predictions}

P1. Relative independence. Following the assumption that the defensive and expansive systems are relatively independent, the present theory predicts that both general and facet-level measures of defensiveness and expansiveness will not strongly correlate. This prediction is supported by evidence of general and facet-level measures. Regarding general measures, recent meta-analytic evidence shows moderate correlations between neuroticism (a relatively general measure of defensiveness) and the expansive needs for competence, relatedness and autonomy (Anglim et al., 2020, Table 4; van den Broeck et al., 2016, Table 2). Facet-level evidence of comparisons between complementary elements of the defensive and expansive systems also supports this prediction, and includes low correlations between threat and challenge appraisals (Rowley, Roesch, Jurica, \& Vaughn, 2005; Roesch \& Rowley, 2005; Durak \& Senol-Durak, 2013, Table 2), low correlations between approach and avoidance, and between 
mastery and performance goals (Darnon et al., 2010, Table 1; Barron \& Harackiewicz, 2001, Table 3; Midgley et al., 1998; Elliot \& Church, 1997, Table 3) and low to moderate correlations between negative defensive affect and positive expansive affect $^{5}$ (Schimmack, 2008; Thompson, 2007).

P2. Defensiveness-expansiveness correlation. The assumption of an hedonic nexus between the expansive and defensive systems leads to the prediction that general measures of expansiveness and defensiveness will negatively correlate, such that lower levels of competence, relatedness and autonomy will be associated with lower levels of security and higher levels of defensiveness. This prediction is supported by the aforementioned meta-analyses, which show moderate negative correlations between neuroticism and the needs for competence, relatedness and autonomy (Anglim et al., 2020, Table 4; van den Broeck et al., 2016, Table 2).

P3. Motivation-consciousness correlation. It was assumed above that defensive processes evolved by detecting and reducing environmental threats. From this assumption follows the prediction that defensiveness will positively correlate with ecological consciousness. The most direct evidence in this regard would be associations between a general measure of defensiveness (e.g., neuroticism) and measures of external (vs. internal) focus of attention. However, there appear to be no such studies in the available literature. Indirect evidence comes from studies that examine the relation between mindfulness and personality: a meta-analysis of the extant evidence shows that neuroticism has a moderate negative correlation with mindfulness (Giluk, 2009). Given that mindfulness involves being more metaconscious of sensations, emotions, thoughts, impulses, etc., the aforementioned correlation implies that higher neuroticism is associated with less metaconsciousness and, therefore, with more ecological consciousness of those mental contents. One problem with that line of evidence, however, is that the concept of mindfulness potentially involves components other than meta-awareness, such as acceptance, which could also be responsible for the observed correlation. Fortunately, there is at least one mindfulness measure which does not involve an acceptance element: the Mindful Attention Awareness Scale (MAAS) measures solely the element of awareness and it still displays the same moderate negative correlation with neuroticism (Brown \& Ryan, 2003, Table 4). Convergently, neuroscientific evidence shows that defensive responses are often automatically controlled by environmental, threatening stimuli and that such responses can be activated even in the absence of conscious recognition of their eliciting stimuli (Öhman, 2005).

Additionally, it was assumed earlier that metaconsciousness can be motivated by expansive needs: the need for competence can prompt self-exploration and self-questioning; the need for relatedness and social competence can motivate self-attention and self-regulation in order to avoid hurting others; the need for autonomy can motivate self-attention and down-regulation of impulses, emotions or attitudes that are not consistent with the individual's deepest values and interests. This assumption leads to predict that general measures of expansiveness and metaconsciousness will be positively correlated or, alternatively, that general measures of metaconsciousness will positively correlate with general measures of the needs for competence, relatedness and autonomy. This prediction is supported by studies showing small to moderate positive correlations between expansive needs and internal state awareness (Harrington \& Loffredo, 2010, Table 2) and expansive needs and mindfulness (Brown \& Ryan, 2003, Table 4; Decuypere, Audenaert, \& Decramer, 2018, Table 3).

\footnotetext{
${ }^{5}$ It is being assumed here that the negative affect scales of several questionnaires (e.g., the PANAS) measure defensive affect whereas the corresponding positive affect scales measure positive expansive affect.
} 
P4. Regulation-affect correlations. It has been a central assumption of this theory that ENDMA, especially in the context of self-threats, is necessary for optimal development and satisfaction of defensive and expansive needs. In this sense, it was posited above that defensive regulation of self-threats maintains threat appraisals and is an important cause of psychological fragmentation. This assumption leads to the prediction that measures of defensive regulation will correlate positively with distress and negative affect. This prediction is supported by findings showing that neuroticism predicts negative affect (Anglim et al., 2019, Table 4), guilt and shame (Abe, 2004, Table 1), self-esteem contingency (Sowislo, Orth, \& Meier, 2014, Table 1; Zeigler-Hill, Clark, \& Pickard, 2008, Table 1), psychopathology (Kotov, Gamez, Schmidt, \& Watson, 2010) and maladaptive self-regulatory strategies (Barańczuk, 2019, Table 1; Connor-Smith, \& Flachsbart, 2007, Table 7).

On the other hand, it was assumed that expansive regulation (in the form of ENDMA as a response to self-threats) down-regulates threat appraisals and is a cause of psychological integration. This assumption leads to the prediction that measures of expansive regulation (i.e., ENDMA) will correlate positively with well-being and positive affect, and negatively with negative affect and distress. Evidence for this prediction includes: (a) negative correlations between internal state awareness and guilt and shame (Watson et al., 1996, Table 2) and depression (Reeves, Watson, Ramsey, \& Morris, 1995, Table 2); (b) positive and negative correlations between mindfulness and positive and negative affect, respectively (Giluk, 2009, Table 1), and negative correlations between mindfulness and psychological symptoms (Baer, Smith, Hopkins, Krietemeyer, \& Toney, 2006, Table 2), self-criticism, inadequacy and self-hate (Cunha \& Paiva, 2012, Table 3), guilt (Friese \& Hofmann, 2016), shame (Woods \& Proeve, 2014, Table 1), and depression and the self-consciousness facet of neuroticism (Brown \& Ryan, 2003, Table 4); and (c) negative correlations between emotional intelligence and depression (Mikolajczak, Luminet, \& Menil, 2006) and shame (Mikolajczak, Nelis, Hansenne, \& Quoidbach, 2008, Table 2).

The assumption that ENDMA down-regulates defensiveness is further supported by a number of studies that show that mindfulness modulates, moderates or mediates the effects of neuroticism on depressive symptoms (Barnhofer, Duggan, \& Griffith, 2011), physical health and symptoms (O'Loughlin, Fryer, \& Zuckerman, 2019), neuroendocrine and affective responses (Brown, Weinstein, \& Creswell, 2012), anger, depressive symptoms and negative emotional reactivity (Feltman, Robinson, \& Ode, 2009), subjective and psychological well-being (Iani, Lauriola, Cafaro, \& Didonna, 2017; Wenzel, von Versen, Hirschmüller, \& Kubiak, 2015), and self-control and impulsivity (Fetterman, Robinson, Ode, \& Gordon, 2010). Additionally, mindfulness has been found to modulate neural responses to high-arousal, unpleasant images (Brown, Goodman, \& Inzlicht, 2013).

P5. Regulation-relationships correlations. The present theory assumes that defensive regulation results in the maintenance of self-threat appraisals. In the context of interpersonal relationships, the maintenance of self-threats is assumed to lead to more defensive responses and a deterioration of those relationships. This assumption leads to the prediction that general measures of defensiveness will negatively correlate with general measures of the need for relatedness. This prediction is supported by recent meta-analytic evidence showing that neuroticism and the need for relatedness are negatively correlated (Anglim et al., 2020, Table 4; van den Broeck et al., 2016, Table 2), meaning that higher defensiveness is associated with less satisfactory interpersonal relationships.

With regard to expansive regulation, it was assumed that ENDMA down-regulates self-threats. In the context of interpersonal relationships, this is assumed to result in less defensive responses. This assumption leads to the prediction that general measures of ENDMA will positively correlate with general 
measures of the need for relatedness. This prediction is supported by studies that have found positive correlations between mindfulness and the need for relatedness (Brown \& Ryan, 2003, Table 4; Decuypere, Audenaert, \& Decramer, 2018, Table 3; Pratscher, Rose, Markovitz, \& Bettencourt, 2018), which means that higher mindfulness is associated with more satisfactory interpersonal relationships.

P6. Regulation-need-satisfaction correlations. One of the most important assumptions of the present theory is that defensive regulation as a long-term strategy to cope with self-threats thwarts psychological needs whereas expansive regulation satisfies them. Defensive regulation of self-threats sustains the appraisal and perception of self-threat (thwarting security), leads to negative, aggressive and less caring and affectionate interactions with others (thwarting relatedness), prevents self-exploration, self-questioning and learning (thwarting competence), and diminishes authenticity and self-congruence (thwarting autonomy). Expansive regulation, in turn, suspends defensive responses and reappraises self-threats as thoughts, ideas or as products of one's identification (restoring security), connects us deeply to ourselves, others and the world (supporting relatedness), promotes self-exploration and learning (supporting competence), and fosters authenticity and self-congruence (supporting autonomy). This assumption leads to the prediction that, in the context of self-threats, general measures of defensive and expansive regulation will, respectively, tend to thwart and satisfy psychological needs. Evidence for the prediction that defensive regulation thwarts expansive needs stems from meta-analyses that find negative correlations between neuroticism and the needs for competence, autonomy and relatedness (Anglim et al., 2020, Table 4; van den Broeck et al., 2016, Table 2). On the other hand, evidence for the prediction that expansive regulation satisfies psychological needs stems from a meta-analytic study showing a negative correlation between mindfulness and neuroticism (Giluk, 2009, Table 1) and various studies displaying positive correlations between mindfulness and the needs for competence, autonomy and relatedness (Brown \& Ryan, 2003, Table 4; Decuypere, Audenaert, \& Decramer, 2018, Table 3).

\section{Conclusion}

The present theory provides a conceptual framework to better understand and regulate the psychologically and socially destructive potential derived from defensiveness. Furthermore, it provides the complementary perspective, namely the psychological conditions required for optimal individual development and optimal satisfaction of psychological needs.

This article presented a macro theory of self-regulation that integrates the concepts of psychological needs and levels of consciousness, and is framed within the paradigm of biological evolution. The first assumption of the theory is the coexistence of two psychological systems of thoughts, emotions and behaviors organized by complementary needs: a defensive system motivated by the need for physical and psychological security and whose function is to protect the organism by avoiding perceived dangers and approaching perceived resources; and an expansive system motivated by the needs for competence, relatedness and autonomy, and whose function is to foster the organism's development by promoting the assimilation of the external and internal worlds, the acquisition of adaptive knowledge and skills, and the establishment of social support by means of positive interpersonal relationships. It was postulated that refective defensiveness-i.e., the defensive psychological processes and behaviors motivated by self-threats, as opposed to survival threats-is the chief cause of psychological distress and negative interpersonal relationships. The distinction between these two psychological systems has the 
potential to integrate a vast diversity of phenomena and constructs that are generally treated in theoretical and empirical isolation.

The second assumption of the theory is a threefold distinction of psychological processes with regard to consciousness, as being either nonconscious, conscious, or metaconscious. The concept of metaconsciousness refers to reflective attention to, and awareness of, one's psychological states and processes, and is of key relevance to self-regulation. On the basis of these two assumptions, the coexistence of two self-regulatory modes was postulated: a defensive self-regulation motivated by security versus an expansive self-regulation motivated by competence, relatedness and autonomy. Defensive regulation is relevant in the context of perceived threats to life or self, and consists of self-protective reactions like avoidance, escape and fight. Expansive regulation refers here to non-defensive metaconsciousness of the own psychological states and processes in both defensive and non-defensive contexts. With the evolutionary emergence of self-reflection, defensive regulation has growing benefits and costs, and the reduction of its costs requires the down-regulation of reflective defensiveness. The defensive regulation of self-threats maintains the very identifications, interpretations and evaluations of self, others and the world that give rise to self-threats in the first place. What is called for in the context of self-threats, is non-defensive metaconsciousness of those interpretations, evaluations and identifications. Non-defensive metaconsciousness down-regulates self-threats and anxiety by way of weakening of their underlying identifications, interpretations and evaluations. Due to this down-regulation of self-threats, expansive regulation causes a reduction of psychological distress and an improvement of the quality of interpersonal relationships.

The most important prediction of this theory is that defensive and expansive regulation of self-threats cause psychological distress and well-being, as well as with negative and positive interpersonal relationships, respectively. Tentative evidence was provided for all predictions.

Our identifications, evaluations and interpretations of self, others and the world lie at the heart of our pressing human problems, whether psychological, social, political, economic or environmental in nature. Because expansive regulation involves the non-defensive metaconsciousness and modification of those identifications, evaluations and interpretations, it might be considered a particularly subtle manifestation of intelligence. Not only is expansive regulation necessary to reduce psychological distress and achieve optimal well-being, but also to actualize the individual's full potential. From a broader perspective, I believe that a global culture of expansive regulation is strictly necessary if we are to survive our most destructive potential as a species, and to forge a sustainable, peaceful and prosperous future for humanity.

\section{Acknowledgements}

I am deeply thankful and indebted to my parents, Isabel Hernández Negrín and Esteban Rojas Nieto, for their continued and unconditional support and feedback over the years-and without which this work would not exist. I also wish to acknowledge the continued feedback of our friend José Parés Pérez.

\section{References}

Abe, J. A. (2004). Shame, guilt, and personality judgment. Journal of Research in Personality, 38(2), 85-104. 
Anglim, J., Horwood, S., Smillie, L. D., Marrero, R. J., \& Wood, J. K. (2020). Predicting psychological and subjective well-being from personality: A meta-analysis. Psychological Bulletin, 146(4), 279.

Assor, A., Roth, G., \& Deci, E. L. (2004). The emotional costs of parents' conditional regard: A Self-Determination Theory analysis. Journal of personality, 72(1), 47-88.

Baer, R. A., Smith, G. T., Hopkins, J., Krietemeyer, J., \& Toney, L. (2006). Using self-report assessment methods to explore facets of mindfulness. Assessment, 13(1), 27-45.

Baird, B., Smallwood, J., Fishman, D. J., Mrazek, M. D., \& Schooler, J. W. (2013). Unnoticed intrusions: Dissociations of meta-consciousness in thought suppression. Consciousness and Cognition, 22(3), 1003-1012.

Bandura, A. (1982). Self-efficacy mechanism in human agency. American Psychologist, 37(2), 122-147.

Bandura, A. (1991). Social cognitive theory of self-regulation. Organizational behavior and human decision processes, 50(2), 248-287.

Barańczuk, U. (2019). The five factor model of personality and emotion regulation: A meta-analysis. Personality and Individual Differences, 139, 217-227.

Bargh, J. A. (1990). Auto-motives: Preconscious determinants of social interaction. In E. T. Higgins \& R. M. Sorrentino (Eds.), Handbook of motivation and cognition: Vol. 2. Foundations of social behavior (pp. 93-130). New York: Guilford Press.

Bargh, J. A. (1994). The four horsemen of automaticity: Awareness, intention, efficiency, and control in social cognition. In R. J. Wyer \& T. K. Srull (Eds.), Handbook of social cognition (pp. 1-40). Hillsdale, NJ: Lawrence Erlbaum Associates, Inc.

Bargh, J. A., \& Gollwitzer, P. M. (1994). Environmental control over goal-directed action. Nebraska Symposium on Motivation, 41, 71-124.

Bargh, J. A., \& Fitzsimons, G. M. (2004). Automatic self-regulation. In In Baumeister, R. F., \& Vohs, K. D. (Eds.) Handbook of self-regulation: Research, theory, and applications, 151-170. The Guilford Press.

Barnhofer, T., Duggan, D. S., \& Griffith, J. W. (2011). Dispositional mindfulness moderates the relation between neuroticism and depressive symptoms. Personality and individual differences, 51(8), 958-962.

Barron, K. E., \& Harackiewicz, J. M. (2001). Achievement goals and optimal motivation: Testing multiple goal models. Journal of personality and social psychology, 80(5), 706.

Batson, C. D., \& Shaw, L. L. (1991). Evidence for altruism: Toward a pluralism of prosocial motives. Psychological inquiry, 2(2), 107-122. 
Baumann, D. J., Cialdini, R. B., \& Kendrick, D. T. (1981). Altruism as hedonism: Helping and self-gratification as equivalent responses. Journal of Personality and Social Psychology, 40(6), 1039-1046.

Baumeister, R. F., Bratslavsky, E., Finkenauer, C., \& Vohs, K. D. (2001). Bad is stronger than good. Review of general psychology, 5(4), 323-370.

Baumeister, R. F., Heatherton, T. F., \& Tice, D. M. (1994). Losing control: How and why people fail at self-regulation. San Diego, CA: Academic Press.

Baumeister, R. F., \& Leary, M. R. (1995). The need to belong: desire for interpersonal attachments as a fundamental human motivation. Psychological bulletin, 117(3), 497-597.

Baumeister, R. F., Bratslavsky, E., Muraven, M., \& Tice, D. M. (1998). Ego depletion: Is the active self a limited resource?. Journal of personality and social psychology, 74(5), 1252.

Baumeister, R. F. (2002). Ego depletion and self-control failure: An energy model of the self's executive function. Self and identity, 1(2), 129-136.

Baumeister, R. F., Schmeichel, B. J., \& Vohs, K. D. (2007). Self-regulation and the executive function: The self as controlling agent. Social psychology: Handbook of basic principles, 2, 516-539.

Bechara, A., \& Damasio, A. R. (2005). The somatic marker hypothesis: A neural theory of economic decision. Games and economic behavior, 52(2), 336-372.

Beck, A. T., Emery, G., \& Greenberg, R. L. (1985). Anxiety disorders and phobias: A cognitive perspective. Basic Books.

Benita, M., Roth, G., \& Deci, E. L. (2014). When are mastery goals more adaptive? It depends on experiences of autonomy support and autonomy. Journal of Educational Psychology, 106(1), 258.

Biggs, J. (2001). Enhancing learning: A matter of style of approach. In R. Sternberg \& L. Zhang (Eds.), Perspectives on cognitive, learning, and thinking styles (pp. 73-102). Mahwah, NJ: Erlbaum.

Bohm, D. (1996). Appendix: physics and perception. In The Special Theory of Relativity (pp. 142-173). Routledge, London.

Bower, G. H. (1993). The fragmentation of psychology? American Psychologist, 48, 905-907.

Bowlby, J. (1969). Attachment and loss: Attachment. New York: Basic Books. 
Bowlby, J. (1988). A secure base: Parent-child attachment and healthy human development. New York: Basic Books.

Brown, K. W., Goodman, R. J., \& Inzlicht, M. (2013). Dispositional mindfulness and the attenuation of neural responses to emotional stimuli. Social cognitive and affective neuroscience, 8(1), 93-99.

Brown, K. W., \& Ryan, R. M. (2003). The Benefits of Being Present: Mindfulness and Its Role in Psychological Well-Being. Journal of Personality and Social Psychology, 84(4), 822-848.

Brown, K. W., Weinstein, N., \& Creswell, J. D. (2012). Trait mindfulness modulates neuroendocrine and affective responses to social evaluative threat. Psychoneuroendocrinology, 37(12), 2037-2041.

Burnkrant, R. E., \& Page Jr, T. J. (1984). A modification of the Fenigstein, Scheier, and Buss self-consciousness scales. Journal of personality assessment, 48(6), 629-637.

Bushman, B. J. (2002). Does venting anger feed or extinguish the flame? Catharsis, rumination, distraction, anger, and aggressive responding. Personality and Social Psychology Bulletin, 28, 724-731.

Byrne, R. W. (2013). Animal curiosity. Current Biology, 23(11), 469-470.

Cacioppo, J. T., Berntson, G. G., Norris, C. J., \& Gollan, J. K. (2012). The Evaluative Space Model. In, van Lange, P. A. M., A. W. Kruglanski, and E. T. Higgins. Handbook of Theories of Social Psychology (pp. 50-72). SAGE Publications.

Cacioppo, J., Larsen, J., Smith, N., \& Berntson, G. (2004). What Lurks below the Surface of Feelings. In Feelings and emotions: The Amsterdam symposium (pp. 223-242).

Cannon, W. B. (1915). Bodily Changes in Pain, Hunger, Fear and Rage. New York: Appleton-Century.

Caprara, G. V., \& Vecchione, M. (2013) Personality approaches to political behavior. In Huddy, L., Sears, D. O., \& Levy, J. S. (Eds.). The Oxford handbook of political psychology. Oxford University Press.

Carver, C. S., \& Scheier, M. F. (1981). Attention and self-regulation: A control-theory approach to human behavior. New York: Springer Verlag.

Carver, C. S., \& Scheier, M. F. (1998). On the self-regulation of behavior. New York: Cambridge University Press.

Carver, C. S., \& Scheier, M. F. (2016). Self-regulation of action and affect. In Vohs, K. D., \& Baumeister, R. F. (Eds.). Handbook of self-regulation: Research, theory, and applications, Third Edition. Guilford Publications. 
Cassidy, J. (2016). The nature of the child's ties. In Cassidy, J., \& Shaver, P. R. (Eds.). Handbook of attachment: Theory, research, and clinical applications (pp. 3-24). Guilford Press.

Chalmers, D. J. (1996). The conscious mind: In search of a fundamental theory. Oxford University Press.

Champagne, F., Diorio, J., Sharma, S., \& Meaney, M. J. (2001). Naturally occurring variations in maternal care in the rat are associated with differences in estrogen-inducible central oxytocin receptors.

Proceedings of the National Academy of Sciences USA, 98, 12736-12741.

Chin, J. M., \& Schooler, J. W. (2009). Meta-awareness. In Banks, W. P. (Ed.). Encyclopedia of consciousness, 2 (pp. 33-41). Academic Press.

Choe, J. C., \& Crespi, B. J. (Eds.). (1997). The evolution of social behaviour in insects and arachnids. Cambridge: Cambridge University Press.

Claessens, S. E., Daskalakis, N. P., van der Veen, R., Oitzl, M. S., de Kloet, E. R., \& Champagne, D. L. (2011). Development of individual differences in stress responsiveness: an overview of factors mediating the outcome of early life experiences. Psychopharmacology, 214(1), 141-154.

Cohen, J. D., McClure, S. M., \& Yu, A. J. (2007). Should I stay or should I go? How the human brain manages the trade-off between exploitation and exploration. Philosophical Transactions of the Royal Society B: Biological Sciences, 362(1481), 933-942.

Cohen, S., Janicki-Deverts, D., \& Miller, G. E. (2007). Psychological stress and disease. Jama, 298(14), 1685-1687.

Costa, P.T. Jr. and McCrae, R.R. (1992) Revised NEO Personality Inventory (NEO-PI-R) and NEO Five-Factor Inventory (NEO-FFI) Professional Manual. Odessa, FL: PsychologicalAssessment Resources

Crespi, B. J. (2001). Evolution of sociality. In Smelser, N. J., and Baltes, P. B. (Eds.) International Encyclopedia of the Social \& Behavioral Sciences (pp. 14504-14507). Pergamon Press.

Cunha, M., \& Paiva, M. J. (2012). Text anxiety in adolescents: The role of self-criticism and acceptance and mindfulness skills. The Spanish Journal of Psychology, 15(2), 533.

Darnon, C., Dompnier, B., Gilliéron, O., \& Butera, F. (2010). The interplay of mastery and performance goals in social comparison: A multiple-goal perspective. Journal of Educational Psychology, 102(1), 212.

de Charms, R. (1968). Personal causation: The internal affective determinants of behavior. New York: Academic Press. 
Decuypere, A., Audenaert, M., \& Decramer, A. (2018). When mindfulness interacts with neuroticism to enhance transformational leadership: the role of psychological need satisfaction. Frontiers in psychology, 9,2588 .

Deutsch, M. (2006). Cooperation and competition. In Deutsch, M., Coleman, P. T., \& Marcus, E. C. (Eds.). (2006). The handbook of conflict resolution: Theory and practice (p. 23-42). John Wiley \& Sons.

Di Domenico, S. I., \& Ryan, R. M. (2017). The emerging neuroscience of intrinsic motivation: a new frontier in self-determination research. Frontiers in Human Neuroscience, 11, 145.

Diehl, M. (1990). The minimal group paradigm: Theoretical explanations and empirical findings. European review of social psychology, 1(1), 263-292.

Diener, Ed. (1984) Subjective Well-Being. Psychological Bulletin, 95(3): 542-575.

Dittmar, H., Bond, R., Hurst, M., \& Kasser, T. (2014). The relationship between materialism and personal well-being: A meta-analysis. Journal of personality and social psychology, 107(5), 879.

Dozois, D. J., Dobson, K. S., \& Rnic, K. (2019). Historical and philosophical bases of the cognitive-behavioral therapies. In Dobson, K. S. and Dozois, D. J. Handbook of cognitive-behavioral therapies, Fourth edition. New York: Guilford Press.

Duckworth, A. L., \& Seligman, M. E. P. (2005). Self-discipline outdoes IQ in predicting academic performance of adolescents. Psychological Science, 16(12), 939-944.

Durak, M., \& Senol-Durak, E. (2013). The development and psychometric properties of the Turkish version of the Stress Appraisal Measure. European Journal of Psychological Assessment.

Duval, S., \& Wicklund, R. A. A theory of objective self-awareness. New York: Academic Press, 1972.

Dworkin, G. B. (1988). The theory and practice of autonomy. Cambridge, UK: Cambridge University Press.

Edelman, G. M. (1992). Bright air, brilliant fire: On the matter of the mind. New York: Basic Books.

Einstein, D., \& Lanning, K. (1998). Shame, guilt, ego development and the five-factor model of personality. Journal of Personality, 66(4), 555-582.

Elliot, A. J. (1999). Approach and avoidance motivation and achievement goals. Educational psychologist, 34(3), 169-189. 
Elliot, A. J., \& Church, M. A. (1997). A hierarchical model of approach and avoidance achievement motivation. Journal of personality and social psychology, 72(1), 218.

Feltman, R., Robinson, M. D., \& Ode, S. (2009). Mindfulness as a moderator of neuroticism-outcome relations: A self-regulation perspective. Journal of Research in Personality, 43(6), 953-961.

Fetterman, A. K., Robinson, M. D., Ode, S., \& Gordon, K. H. (2010). Neuroticism as a risk factor for behavioral dysregulation: A mindfulness-mediation perspective. Journal of Social and Clinical Psychology, 29(3), 301-321.

Finkel, E. J., Fitzsimons, G. M., \& vanDellen, M. R. (2016). Self-regulation as a transactive process: Reconceptualizing the unit of analysis for goal setting, pursuit, and outcomes. In Baumeister, R. F., \& Vohs, K. D. (Eds.) Handbook of self-regulation: Research, theory, and applications, Third Edition (p. 264-282). The Guilford Press.

Friedman, M. (2003). Autonomy, gender, politics. New York: Oxford University Press.

Friese, M., \& Hofmann, W. (2016). State mindfulness, self-regulation, and emotional experience in everyday life. Motivation Science, 2(1), 1.

Foa, E. B., Huppert, J. D., \& Cahill, S. P. (2006). Emotional processing theory: An update. In Rothbaum, B. O. (Ed.) Pathological anxiety: Emotional processing in etiology and treatment. The Guilford Press.

Frijda, N. H. (1988). The laws of emotion. American psychologist, 43(5), 349.

Frijda, N. H. (2007). The laws of emotion. Psychology Press, p. 123.

Gaj, N. (2016). Unity and fragmentation in psychology: The philosophical and methodological roots of the discipline. Routledge.

Gallup, G. G. (1970). Chimpanzees: self-recognition. Science, 167(3914), 86-87.

Giluk, T. L. (2009). Mindfulness, Big Five personality, and affect: A meta-analysis. Personality and Individual Differences, 47(8), 805-811.

Gottfredson, M., \& Hirschi, T. (1990). A general theory of crime. Stanford, CA: Stanford University Press.

Green, J. D., \& Campbell, W. K. (2000). Attachment and exploration in adults: Chronic and contextual accessibility. Personality and Social Psychology Bulletin, 26(4), 452-461. 
Greenberg, J., Solomon, S., \& Pyszczynski, T. (1997). Terror management theory of self-esteem and cultural worldviews: Empirical assessments and conceptual refinements. In Advances in experimental social psychology (Vol. 29, pp. 61-139). Academic Press.

Gross, J. J. (2014). Emotion regulation: Conceptual and empirical foundations. In Gross, J. J. (Ed.). Handbook of emotion regulation. Guilford publications.

Güzuldere, G. (1997). The many faces of consciousness: A field guide. In Block, N. J., Flanagan, O. J., \& Güzeldere, G. (Eds.). The nature of consciousness: Philosophical debates. MIT press.

Ha, R. R. (2010). Cost-Benefit Analysis. In Breed, M. D., \& Moore, J. (Eds.). Encyclopedia of animal behavior. Academic Press.

Harrington, R., \& Loffredo, D. A. (2010). Insight, rumination, and self-reflection as predictors of well-being. The Journal of psychology, 145(1), 39-57.

Heine, S. J., Proulx, T., \& Vohs, K. D. (2006). The meaning maintenance model: On the coherence of social motivations. Personality and social psychology review, 10(2), 88-110.

Helbig-Lang, S., \& Petermann, F. (2010). Tolerate or eliminate? A systematic review on the effects of safety behavior across anxiety disorders. Clinical Psychology: Science and Practice, 17(3), 218-233.

Higgins, E. T. (1997). Beyond pleasure and pain. American Psychologist, 52, 1280-1300.

Higgins, E. T., \& Spiegel, S. (2004). Promotion and prevention strategies for self-regulation: A motivated cognition perspective. In Baumeister, R. F., \& Vohs, K. D. (Eds.) Handbook of self-regulation: Research, theory, and applications (p. 171-187). The Guilford Press.

Hirschi, T. (2004). Self-control and crime. In Baumeister, R. F., \& Vohs, K. D. (Eds.) Handbook of self-regulation: Research, theory, and applications (p. 538-552). The Guilford Press.

Hofstede, G. (2011). Dimensionalizing cultures: The Hofstede model in context. Online readings in psychology and culture, 2(1), 8.

Hölzel, B. K., Lazar, S. W., Gard, T., Schuman-Olivier, Z., Vago, D. R., \& Ott, U. (2011). How does mindfulness meditation work? Proposing mechanisms of action from a conceptual and neural perspective. Perspectives on psychological science, 6(6), 537-559.

Iani, L., Lauriola, M., Cafaro, V., \& Didonna, F. (2017). Dimensions of mindfulness and their relations with psychological well-being and neuroticism. Mindfulness, 8(3), 664-676. 
Inzlicht, M., \& Schmeichel, B. J. (2016). Beyond limited resources: Self-control failure as the product of shifting priorities. In Baumeister, R. F., \& Vohs, K. D. (Eds.) Handbook of self-regulation: Research, theory, and applications, Third Edition (p. 165-181). The Guilford Press.

Jansen, A. S., Van Nguyen, X., Karpitskiy, V., Mettenleiter, T. C., \& Loewy, A. D. (1995). Central command neurons of the sympathetic nervous system: basis of the fight-or-flight response. Science, 270(5236), 644-646.

Jerusalem, M., \& Schwarzer, R. (1992). Self-efficacy as a resource factor in stress appraisal processes. In Schwarzer, R. (2014). Self-efficacy: Thought control of action (pp. 195-213). Taylor \& Francis.

Jones, C. R., Kirkland, T., \& Cunningham, W. A. (2014). Attitudes, evaluation, and emotion regulation. In Gross, J. J. (Ed.) Handbook of emotion regulation (pp. 251-266). Guilford publications.

Kabat-Zinn, J. (1994). Wherever you go, there you are: Mindfulness meditation for everyday life. London: Piatkus.

Kandel, E. R., Schwartz, J. H., \& Jessell, T. M. (2000). Principles of neural science, 4th ed. (p. 901) McGraw-Hill, New York.

Kernis, M. H. (2003). Toward a conceptualization of optimal self-esteem. Psychological inquiry, 14(1), $1-26$.

Kernis, M. H., \& Goldman, B. M. (2006). A multicomponent conceptualization of authenticity: Theory and research. Advances in experimental social psychology, 38, 283-357.

Kihlstrom, J. F., Beer, J. S., \& Klein, S. B. (2003). Self and identity as memory. In M. R. Leary \& J. P. Tangney (Eds.), Handbook of self and identity (pp. 68-90). New York: Guilford Press.

Kihlstrom, J. F. (2007). The psychological unconscious. In John, O. P., Robins, R. W., \& Pervin, L. A. (Eds.), Handbook of personality: Theory and research, Third Edition (pp. 583-602). Guilford Press.

Killingsworth, M. A., \& Gilbert, D. T. (2010). A wandering mind is an unhappy mind. Science, 330(6006), 932-932.

Koestner, R., \& Losier, G. F. (1996). Distinguishing reactive versus reflective autonomy. Journal of Personality, 64(2), 465-494.

Komarraju, M., Karau, S. J., Schmeck, R. R., \& Avdic, A. (2011). The Big Five personality traits, learning styles, and academic achievement. Personality and individual differences, 51(4), 472-477.

Kotov, R., Gamez, W., Schmidt, F., \& Watson, D. (2010). Linking "big" personality traits to anxiety, depressive, and substance use disorders: a meta-analysis. Psychological bulletin, 136(5), 768. 
Kouider, S., \& Dehaene, S. (2007). Levels of processing during non-conscious perception: a critical review of visual masking. Philosophical Transactions of the Royal Society B: Biological Sciences, 362(1481), 857-875.

Kross, E., \& Ayduk, O. (2017). Self-distancing: Theory, research, and current directions. In Advances in experimental social psychology (Vol. 55, pp. 81-136). Academic Press.

Larsen, R. J., \& Prizmic, Z. (2008). Regulation of emotional well-being. In Eid, M., \& Larsen, R. J. (Eds.). The science of subjective well-being (pp. 258-89). Guilford Press.

Lazarus, R. S. (1966). Psychological stress and the coping process. New York: McGraw Hill.

Lazarus, R. S., \& Folkman, S. (1984). Stress, appraisal, and coping. New York: Springer.

Lazarus, R. S. (1991a). Emotion and adaptation. New York: Oxford University Press.

Lazarus, R. S. (1991b). Progress on a cognitive-motivational-relational theory of emotion. American psychologist, 46(8), 819.

Leary, M. R., \& Baumeister, R. F. (2000). The nature and function of self-esteem: Sociometer theory. In M.P. Zanna (Ed.), Advances in experimental social psychology (Vol. 32, pp. 1-62). San Diego: Academic Press.

Leary, M. R. (2004). The sociometer, self-esteem, and the regulation of interpersonal behavior. In Baumeister, R. F., \& Vohs, K. D. (Eds.) Handbook of self-regulation: Research, theory, and applications, 374-392. The Guilford Press.

Leary, M. R. (2004). The curse of the self: Self-awareness, egotism, and the quality of human life. Oxford University Press.

Leary, M. R., \& Tangney, J. P. (2012). The self as an organizing construct in the behavioral and social sciences. In M. R. Leary \& J. P. Tangney (Eds.), Handbook of self and identity (pp. 1-18). New York, NY, US: Guilford Press.

Lee-Baggley, D., Preece, M., \& DeLongis, A. (2005). Coping with interpersonal stress: Role of Big Five traits. Journal of personality, 73(5), 1141-1180.

LeDoux, J. E. (1996). The emotional brain. New York: Simon \& Schuster.

Lewis, M. (1990). Self-knowledge and social development in early life. In L. A. Pervin (Ed.), Handbook of personality (pp. 277-300). New York: Guilford Press. 
Lewis, M. (2016). Self-Conscious Emotions: Embarrassment, Pride, Shame, Guilt, and Hubris. In Barrett, L. F., Lewis, M., \& Haviland-Jones, J. M. (Eds.). Handbook of emotions. Guilford Publications.

Le Fevre, M., Kolt, G. S., \& Matheny, J. (2006). Eustress, distress and their interpretation in primary and secondary occupational stress management interventions: which way first?. Journal of Managerial Psychology.

Nader, K., \& Einarsson, E. Ö. (2010). Memory reconsolidation: an update. Annals of the New York Academy of Sciences, 1191(1), 27-41.

Nagel, T. (1974). What is it like to be a bat?. The philosophical review, 83(4), 435-450.

Ma, K. (2006). Attachment theory in adult psychiatry. Part 1: Conceptualisations, measurement and clinical research findings. Advances in Psychiatric Treatment, 12(6), 440-449.

Madsen, M. K., Fisher, P. M., Stenbæk, D. S., Kristiansen, S., Burmester, D., Lehel, S., ... \& Knudsen, G. M. (2020). A single psilocybin dose is associated with long-term increased mindfulness, preceded by a proportional change in neocortical 5-HT2A receptor binding. European Neuropsychopharmacology.

Mariotti, A. (2015). The effects of chronic stress on health: new insights into the molecular mechanisms of brain-body communication. Future science $O A, 1(3)$.

Mashour, G. A., \& Alkire, M. T. (2013). Evolution of consciousness: Phylogeny, ontogeny, and emergence from general anesthesia. Proceedings of the National Academy of Sciences, 110 (Supplement 2), 10357-10364.

Mayer, J. D., Salovey, P., \& Caruso, D. R. (2004). Emotional Intelligence: Theory, Findings, and Implications. Psychological inquiry, 15(3), 197-215.

McNarry, A. F., \& Goldhill, D. R. (2004). Simple bedside assessment of level of consciousness: comparison of two simple assessment scales with the Glasgow Coma scale. Anaesthesia, 59(1), 34-37.

Meaney, M. J., Diorio, J., Francis, D., Widdowson, J., LaPlante, P., Caldji, C., ... \& Plotsky, P. M. (1996). Early Environmental Regulation of Forebrain Glucocorticoid Receptor Gene Expression: Implications for Adrenocortical Responses to Stress; pp. 61-72. Developmental neuroscience, 18(1-2), 61-72.

Merker, B. (2007). Consciousness without a cerebral cortex: A challenge for neuroscience and medicine. Behavioral and brain sciences, 30(1), 63-81.

Metcalfe, J., \& Mischel, W. (1999). A hot/cool-system analysis of delay of gratification: dynamics of willpower. Psychological review, 106(1), 3. 
Midgley, C., Kaplan, A., Middleton, M., Maehr, M. L., Urdan, T., Anderman, L. H., ... \& Roeser, R. (1998). The development and validation of scales assessing students' achievement goal orientations. Contemporary educational psychology, 23(2), 113-131.

Mikolajczak, M., Luminet, O., \& Menil, C. (2006). Predicting resistance to stress: Incremental validity of trait emotional intelligence over alexithymia and optimism. Psicothema, 18, 79-88.

Mikolajczak, M., Nelis, D., Hansenne, M., \& Quoidbach, J. (2008). If you can regulate sadness, you can probably regulate shame: Associations between trait emotional intelligence, emotion regulation and coping efficiency across discrete emotions. Personality and individual differences, 44(6), 1356-1368.

Mikulincer, M. (1997). Adult attachment style and information processing: Individual differences in curiosity and cognitive closure. Journal of personality and social psychology, 72(5), 1217.

Mikulincer, M., \& Arad, D. (1999). Attachment working models and cognitive openness in close relationships: A test of chronic and temporary accessibility effects. Journal of personality and social psychology, 77(4), 710.

Mischel, W., \& Ayduk, O. (2004). Willpower in a cognitive-affective processing system. In Baumeister, R. F., \& Vohs, K. D. (Eds.) Handbook of self-regulation: Research, theory, and applications, 99-129. The Guilford Press.

Mitchell, R. W. (2012). Self-recognition in animals. In M. R. Leary \& J. P. Tangney (Eds.), Handbook of self and identity (pp. 656-679). New York, NY, US: Guilford Press.

Moffitt, T. E., Arseneault, L., Belsky, D., Dickson, N., Hancox, R. J., Harrington, H., ... \& Sears, M. R. (2011). A gradient of childhood self-control predicts health, wealth, and public safety. Proceedings of the National Academy of Sciences, 108(7), 2693-2698.

Moscovitch, D. A., Antony, M. M., \& Swinson, R. P. (2009). Exposure-based treatments for anxiety disorders: Theory and process. Oxford handbook of anxiety and related disorders, 461-475.

Ng, J. Y., Ntoumanis, N., Thøgersen-Ntoumani, C., Deci, E. L., Ryan, R. M., Duda, J. L., \& Williams, G. C. (2012). Self-determination theory applied to health contexts: A meta-analysis. Perspectives on Psychological Science, 7(4), 325-340.

Nicholls, J. G., Cobb, P., Wood, T., Yackel, E., \& Patashnick, M. (1990). Assessing students' theories of success in mathematics: Individual and classroom differences. Journal for Research in Mathematics education, 109-122.

Öhman, A. (1986). Face the beast and fear the face: Animal and social fears as prototypes for evolutionary analyses of emotion. Psychophysiology, 23, 123-145. 
Öhman, A. (2005). The role of the amygdala in human fear: automatic detection of threat.

Psychoneuroendocrinology, 30(10), 953-958.

Öhman, A. (2008). Fear and anxiety: Overlaps and dissociations. In M. Lewis, J. M. Haviland-Jones, \& L. F. Barrett (Eds.), Handbook of emotions (p. 709-728). The Guilford Press.

O'Loughlin, R. E., Fryer, J. W., \& Zuckerman, M. (2019). Mindfulness and stress appraisals mediate the effect of neuroticism on physical health. Personality and Individual Differences, 142, 122-131.

Osgood, C. E., May, W. H., \& Miron, M. S. (1975). Cross-cultural universals of affective meaning. University of Illinois Press.

Oyserman, D., Elmore, K., \& Smith, G. (2012). Self, self-concept, and identity. In Leary, M. R., \& Tangney, J. P. (Eds.). Handbook of self and identity (pp. 69-104). Guilford Press.

Panksepp, J. (1998). Affective Neuroscience: The Foundations of Human and Animal Emotions. New York: Oxford University Press.

Panksepp, J., \& Biven, L. (2012). The archaeology of mind: Neuroevolutionary origins of human emotions. New York: W.W. Norton \& Company.

Perry, R. P., \& Hamm, J. M. (2017). An attribution perspective on competence and motivation. In Elliot, A. J., Dweck, C. S., \& Yeager, D. S. (Eds.). Handbook of competence and motivation: Theory and application (pp. 61-84). Guilford Press.

Piaget, J. (1952). The origins of intelligence in children. New York: International Universities Press.

Piaget, J. (1971). Biology and knowledge: An essay on the relations between organic regulations and cognitive processes. Chicago: University of Chicago Press.

Piurko, Y., Schwartz, S. H., \& Davidov, E. (2011). Basic personal values and the meaning of left-right political orientations in 20 countries. Political Psychology, 32(4), 537-561.

Polan, H. J., \& Hofer, M. A. (2016). Psychobiological origins of infant attachment and its role in development. In Cassidy, J., \& Shaver, P. R. (Eds.). Handbook of attachment: Theory, research, and clinical applications, Third Edition (pp. 117-132). Guilford Press.

Pratscher, S. D., Rose, A. J., Markovitz, L., \& Bettencourt, A. (2018). Interpersonal mindfulness: Investigating mindfulness in interpersonal interactions, co-rumination, and friendship quality. Mindfulness, 9(4), 1206-1215.

Premack, D., \& Woodruff, G. (1978). Does the chimpanzee have a theory of mind?. Behavioral and brain sciences, 1(4), 515-526. 
Pyszczynski, T., Greenberg, J., \& Arndt, J. (2012). Freedom versus fear revisited: An integrative analysis of the dynamics of the defense and growth of self. In Leary, M. R., \& Tangney, J. P. (Eds.) Handbook of Self and Identity, Second Edition (pp. 378-404). The Guilford Press.

Quaglia, J. T., Brown, K. W., Lindsay, E. K., Creswell, J. D., \& Goodman, R. J. (2015). From conceptualization to operationalization of mindfulness. In Brown, K. W., Creswell, J. D., \& Ryan, R. M. (Eds.). Handbook of mindfulness: Theory, research, and practice (pp. 151-170). Guilford Publications.

Reeves, A. L., Watson, P. J., Ramsey, A., \& Morris, R. J. (1995). Private self-consciousness factors, need for cognition, and depression. Journal of Social Behavior and Personality, 10(2), 431.

Rial, R. V., Nicolau, M. C., Gamundí, A., Akaârir, M., Garau, C., \& Esteban, S. (2008). The evolution of consciousness in animals. In Liljenström, H., \& Århem, P. (Eds.). Consciousness Transitions:

Phylogenetic, Ontogenetic and Physiological Aspects (pp. 45-76). Elsevier Science BV.

Roth, G., Assor, A., Niemiec, C. P., Ryan, R. M., \& Deci, E. L. (2009). The emotional and academic consequences of parental conditional regard: Comparing conditional positive regard, conditional negative regard, and autonomy support as parenting practices. Developmental psychology, 45(4), 1119.

Rowley, A. A., Roesch, S. C., Jurica, B. J., \& Vaughn, A. A. (2005). Developing and validating a stress appraisal measure for minority adolescents. Journal of Adolescence, 28(4), 547-557.

Roesch, S. C., \& Rowley, A. A. (2005). Evaluating and developing a multidimensional, dispositional measure of appraisal. Journal of personality assessment, 85(2), 188-196.

Ruiz-Mirazo, K., Etxeberria, A., Moreno, A., \& Ibáñez, J. (2000). Organisms and their place in biology. Theory in biosciences, 119(3-4), 209.

Ryan, R. M., \& Connell, J. P. (1989). Perceived locus of causality and internalization: Examining reasons for acting in two domains. Journal of Personality and Social Psychology, 57(5), 749-761.

Ryan, R. M., \& Deci, E. L. (2004). Autonomy is no illusion: Self-determination theory and the empirical study of authenticity, awareness, and will. In J. Greenberg, S. L. Koole, \& T. Pyszczynski (Eds.), Handbook of experimental existential psychology (pp. 449-479). New York: Guilford Press.

Ryan, R. M., \& Deci, E. L. (2017). Self-determination theory: Basic psychological needs in motivation, development, and wellness. Guilford Publications.

Ryan, R. M., Kuhl, J., \& Deci, E. L. (1997). Nature and autonomy: An organizational view of social and neurobiological aspects of self-regulation in behavior and development. Development and psychopathology, 9(4), 701-728. 
Ryff, C. D. (1989). Happiness is everything, or is it? Explorations on the meaning of psychological well-being. Journal of personality and social psychology, 57(6), 1069.

Sampedro, F., de la Fuente Revenga, M., Valle, M., Roberto, N., Domínguez-Clavé, E., Elices, M., ... \& Friedlander, P. (2017). Assessing the psychedelic "after-glow" in ayahuasca users: post-acute neurometabolic and functional connectivity changes are associated with enhanced mindfulness capacities. International Journal of Neuropsychopharmacology, 20(9), 698-711.

Scherer, K. R., Schorr, A., \& Johnstone, T. (Eds.). (2001). Appraisal processes in emotion: Theory, methods, research. Oxford University Press.

Schimmack, U. (2008). The structure of subjective well-being. In Eid, M., \& Larsen, R. J. (Eds.), The science of subjective well-being, 97-123. Guilford Press.

Schooler, J. W. (2001). Discovering memories of abuse in the light of meta-awareness. Journal of Aggression, Maltreatment \& Trauma, 4(2), 105-136.

Schooler, J. W. (2002). Re-representing consciousness: Dissociations between experience and meta-consciousness. Trends in cognitive sciences, 6(8), 339-344.

Schooler, J. W., Smallwood, J., Christoff, K., Handy, T. C., Reichle, E. D., \& Sayette, M. A. (2011). Meta-awareness, perceptual decoupling and the wandering mind. Trends in Cognitive Sciences, 15, 319-326.

Schooler, J. W., Mrazek, M. D., Baird, B., \& Winkielman, P. (2015). Minding the mind: The value of distinguishing among unconscious, conscious, and metaconscious processes. In Mikulincer, M. E., Shaver, P. R. APA handbook of personality and social psychology, Volume 1: Attitudes and Social Cognition (pp. 179-202). American Psychological Association.

Schrödinger, E. (1944). What is life?: The physical aspect of the living cell. Cambridge, UK: Cambridge University Press.

Searle, J. R. (1990). Who is computing with the brain?. Behavioral and Brain Sciences, 13(4), 632-642.

Seth, A. K., Baars, B. J., \& Edelman, D. B. (2005). Criteria for consciousness in humans and other mammals. Consciousness and cognition, 14(1), 119-139.

Selye, H. (1974). Stress without distress. Londres: Hodder \& Stoughton.

Selye, H. (1975). Confusion and controversy in the stress field. Journal of human stress, 1(2), 37-44.

Selye, H. (1976). Stress without distress. In Psychopathology of human adaptation (pp. 137-146).

Springer, Boston, MA. 
Selye, H. (1983). The stress concept: Past, present, and future. In C. L. Cooper (Ed.), Stress research (pp. 1-20). Nueva York: Wiley.

Senko, C., Hulleman, C. S., \& Harackiewicz, J. M. (2011). Achievement goal theory at the crossroads: Old controversies, current challenges, and new directions. Educational psychologist, 46(1), 26-47.

Silk J. B. (2007). The adaptive value of sociality in mammalian groups. Philosophical transactions of the Royal Society of London. Series B, Biological sciences, 362(1480), 539-559.

Smallwood, J. et al. (2008) Segmenting the stream of consciousness: the psychological correlates of temporal structures in the time series data of a continuous performance task. Brain Cognit. 66, 50-56.

Smallwood, J. et al. (2007) The lights are on but no one's home - The decoupling of executive resources when the mind-wanders. Psychon. Bull. Rev. 14, 527-533.

Soler, J., Elices, M., Franquesa, A., Barker, S., Friedlander, P., Feilding, A., ... \& Riba, J. (2016).

Exploring the therapeutic potential of Ayahuasca: acute intake increases mindfulness-related capacities. Psychopharmacology, 233(5), 823-829.

Sowislo, J. F., Orth, U., \& Meier, L. L. (2014). What constitutes vulnerable self-esteem? Comparing the prospective effects of low, unstable, and contingent self-esteem on depressive symptoms. Journal of Abnormal Psychology, 123(4), 737.

Squire, L. R. (1987). Memory and brain. New York, NY, US: Oxford University Press.

Stanley, P. J., Schutte, N. S., \& Phillips, W. J. (2020). A Meta-Analytic Investigation of the Relationship between Basic Psychological Need Satisfaction and Affect. Journal of Positive School Psychology, 1-16.

Sternbach, G. L. (2000). The Glasgow coma scale. The Journal of emergency medicine, 19(1), 67-71.

Sternberg, R. J. (Ed). (2005). Unity in psychology: Possibility or pipedream? Washington, DC: American Psychological Association.

Styles, E. A. (2006). The psychology of attention, Second edition (p. 259). New York: Psychology Press.

Tangney, J. P., Baumeister, R. F., \& Boone, A. L. (2004). High self-control predicts good adjustment, less pathology, better grades, and interpersonal success. Journal of Personality, 72, 271-322.

Taylor, S. E. (1991). Asymmetrical effects of positive and negative events: The mobilization-minimization hypothesis. Psychological Bulletin, 110, 67-85. 
Teixeira, D. S., Marques, M., \& Palmeira, A. L. (2018). Associations between affect, basic psychological needs and motivation in physical activity contexts: Systematic review and meta-analysis. Revista iberoamericana de psicología del ejercicio y el deporte, 13(2), 225-233.

Thompson, E. R. (2007). Development and validation of an internationally reliable short-form of the positive and negative affect schedule (PANAS). Journal of cross-cultural psychology, 38(2), 227-242.

Tooby, J., \& Cosmides, L. (2015). The theoretical foundations of evolutionary psychology. In Buss, D. M. (Ed.), The handbook of evolutionary psychology, Vol. 1: Foundations, 2nd edition (p. 3-87). John Wiley \& Sons.

Trapnell, P. D., \& Campbell, J. D. (1999). Private self-consciousness and the five-factor model of personality: distinguishing rumination from reflection. Journal of personality and social psychology, 76(2), 284.

Vallerand, R. J., \& Houlfort, N. (2003). Passion at work: Toward a new conceptualization. In S. W. Gilliland, D. D. Steiner, \& D. P. Skarlicki (Eds.), Emerging perspectives on values in organizations (pp. 175-204). Greenwich, CT: Information Age Publishing.

van den Broeck, A., Ferris, D. L., Chang, C. H., \& Rosen, C. C. (2016). A review of self-determination theory's basic psychological needs at work. Journal of Management, 42(5), 1195-1229.

von Bertalanffy, L. (1968). General system theory: Foundations, development, applications. New York: George Braziller Inc.

Watson, D., Clark, L. A., \& Tellegen, A. (1988). Development and validation of brief measures of positive and negative affect: the PANAS scales. Journal of personality and social psychology, 54(6), 1063.

Watson, P. J., Morris, R. J., Ramsey, A., Hickman, S. E., \& Waddell, M. G. (1996). Further contrasts between self-reflectiveness and internal state awareness factors of private self-consciousness. The Journal of Psychology, 130(2), 183-192.

Weiner, B. (2005). Motivation from an attribution perspective and the social psychology of perceived competence. In A. J. Elliot \& C. S. Dweck (Eds.), Handbook of competence and motivation (pp. 73-84). New York: Guilford Press.

Wentworth, N., \& Witryol, S. L. (2003). Curiosity, exploration, and novelty-seeking. In M. H. Bornstein, L. Davidson, C. L. M. Keyes, \& K. A. Moore (Eds.), Crosscurrents in contemporary psychology. Well-being: Positive development across the life course (p. 281-294). Lawrence Erlbaum Associates Publishers. 
Wenzel, M., von Versen, C., Hirschmüller, S., \& Kubiak, T. (2015). Curb your neuroticism-Mindfulness mediates the link between neuroticism and subjective well-being. Personality and Individual Differences, $80,68-75$.

White, R. W. (1959). Motivation reconsidered: The concept of competence. Psychological Review, 66(5), 297-333.

White, R. W. (1963). Ego and reality in psychoanalytic theory: A proposal regarding independent ego energies. Madison, CT: International Universities Press.

Winkielman, P., \& Berridge, K. C. (2004). Unconscious emotion. Current directions in psychological science, 13(3), 120-123.

Winkielman, P., Berridge, K. C., \& Wilbarger, J. L. (2005). Unconscious affective reactions to masked happy versus angry faces influence consumption behavior and judgments of value. Personality and Social Psychology Bulletin, 1, pp. 121-135.

Winkielman, P., Berridge, K., \& Sher, S. (2011). Emotion, consciousness, and social behavior. In J. Decety \& J. T. Cacioppo (Eds.), Handbook of social neuroscience (pp 195-211). Oxford University Press.

Winkielman, P., \& Schooler, J. W. (2011). Splitting consciousness: Unconscious, conscious, and metaconscious processes in social cognition. European Review of Social Psychology, 22(1), 1-35.

Woods, H., \& Proeve, M. (2014). Relationships of mindfulness, self-compassion, and meditation experience with shame-proneness. Journal of Cognitive Psychotherapy, 28(1), 20-33.

Wright, J. H., Brown, G. K., Thase, M. E., \& Basco, M. R. (2017). Learning cognitive-behavior therapy: An illustrated guide. American Psychiatric Pub.

Zeigler-Hill, V., Clark, C. B., \& Pickard, J. D. (2008). Narcissistic subtypes and contingent self-esteem: Do all narcissists base their self-esteem on the same domains?. Journal of personality, 76(4), 753-774.

Zhang, T. Y., Chrétien, P., Meaney, M. J., \& Gratton, A. (2005). Influence of naturally occurring variations in maternal care on prepulse inhibition of acoustic startle and the medial prefrontal cortical dopamine response to stress in adult rats. Journal of Neuroscience, 25(6), 1493-1502.

Zimmerman, B. J. (2002). Becoming a self-regulated learner: An overview. Theory into practice, 41(2), 64-70.

Zimmerman, B. J., \& Campillo, M. (2003). Motivating self-regulated problem solvers. In Davidson, J. E., \& Sternberg R. J. (Eds.) The psychology of problem solving, 233-262. Cambridge University Press. 